\title{
Whole brain high-resolution functional imaging at ultra high magnetic fields: an application to the analysis of resting state networks
}

Citation for published version (APA):

de Martino, F., Esposito, F., van de Moortele, P. F., Harel, N., Formisano, E., Goebel, R., Ugurbil, K., \& Yacoub, E. (2011). Whole brain high-resolution functional imaging at ultra high magnetic fields: an application to the analysis of resting state networks. Neuroimage, 57(3), 1031-1044. https://doi.org/10.1016/j.neuroimage.2011.05.008

Document status and date:

Published: 01/08/2011

DOI:

10.1016/j.neuroimage.2011.05.008

Document Version:

Publisher's PDF, also known as Version of record

\section{Document license:}

Taverne

Please check the document version of this publication:

- A submitted manuscript is the version of the article upon submission and before peer-review. There can be important differences between the submitted version and the official published version of record.

People interested in the research are advised to contact the author for the final version of the publication, or visit the DOI to the publisher's website.

- The final author version and the galley proof are versions of the publication after peer review.

- The final published version features the final layout of the paper including the volume, issue and page numbers.

Link to publication

\footnotetext{
General rights rights.

- You may freely distribute the URL identifying the publication in the public portal. please follow below link for the End User Agreement:

www.umlib.nl/taverne-license

Take down policy

If you believe that this document breaches copyright please contact us at:

repository@maastrichtuniversity.nl

providing details and we will investigate your claim.
}

Copyright and moral rights for the publications made accessible in the public portal are retained by the authors and/or other copyright owners and it is a condition of accessing publications that users recognise and abide by the legal requirements associated with these

- Users may download and print one copy of any publication from the public portal for the purpose of private study or research.

- You may not further distribute the material or use it for any profit-making activity or commercial gain

If the publication is distributed under the terms of Article $25 \mathrm{fa}$ of the Dutch Copyright Act, indicated by the "Taverne" license above, 


\title{
Whole brain high-resolution functional imaging at ultra high magnetic fields: An application to the analysis of resting state networks
}

\author{
Federico De Martino a,b,*,1, Fabrizio Esposito ${ }^{\text {a, } 1}$, Pierre-Francois van de Moortele ${ }^{\mathrm{b}}$, Noam Harel ${ }^{\mathrm{b}, \mathrm{c}}$, \\ Elia Formisano ${ }^{\mathrm{a}}$, Rainer Goebel ${ }^{\mathrm{a}}$, Kamil Ugurbil ${ }^{\mathrm{b}}$, Essa Yacoub ${ }^{\mathrm{b}}$ \\ a Department of Cognitive Neurosciences, Faculty of Psychology and Neuroscience, Maastricht University, Maastricht, The Netherlands \\ b Center for Magnetic Resonance Research, Department of Radiology, University of Minnesota, Minneapolis, USA \\ c Department of Neurosurgery, University of Minnesota, Minneapolis, USA
}

\section{A R T I C L E I N F O}

\section{Article history:}

Received 21 December 2010

Revised 1 May 2011

Accepted 3 May 2011

Available online 10 May 2011

\section{Keywords:}

Ultra high field functional magnetic

resonance imaging

Whole brain fMRI

Resting state

Independent component analysis

\begin{abstract}
A B S T R A C T
Whole-brain functional magnetic resonance imaging (fMRI) allows measuring brain dynamics at all brain regions simultaneously and is widely used in research and clinical neuroscience to observe both stimulusrelated and spontaneous neural activity.

Ultrahigh magnetic fields (7 $\mathrm{T}$ and above) allow functional imaging with high contrast-to-noise ratios and improved spatial resolution and specificity compared to clinical fields (1.5 T and $3 \mathrm{~T}$ ). High-resolution $7 \mathrm{~T}$ fMRI, however, has been mostly limited to partial brain coverage with previous whole-brain applications sacrificing either the spatial or temporal resolution.

Here we present whole-brain high-resolution (1, 1.5 and $2 \mathrm{~mm}$ isotropic voxels) resting state fMRI at 7 T, obtained with parallel imaging technology, without sacrificing temporal resolution or brain coverage, over what is typically achieved at $3 \mathrm{~T}$ with several fold larger voxel volumes.

Using Independent Component Analysis we demonstrate that high resolution images acquired at $7 \mathrm{~T}$ retain enough sensitivity for the reliable extraction of typical resting state brain networks and illustrate the added value of obtaining both single subject and group maps, using cortex based alignment, of the default-mode network (DMN) with high native resolution. By comparing results between multiple resolutions we show that smaller voxels volumes ( 1 and $1.5 \mathrm{~mm}$ isotropic) data result in reduced partial volume effects, permitting separations of detailed spatial features within the DMN patterns as well as a better function to anatomy correspondence.
\end{abstract}

(c) 2011 Elsevier Inc. All rights reserved.

\section{Introduction}

Since its introduction (Bandettini et al., 1992; Kwong et al., 1992; Ogawa et al., 1992), functional magnetic resonance imaging (fMRI) has rapidly evolved to become an indispensible method in the pursuit to understand human cognition under normal and perturbed conditions. Despite its indirect nature of functional mapping signals, the fMRI response has a close relationship with the underlying neuronal activity (Logothetis et al., 2001). The magnitude of the mapping signals and their spatial specificity depend on the contrast mechanism $\left(\mathrm{T}_{2}{ }^{*}\right.$ or $\mathrm{T}_{2}$ ) and the field strength employed for the measurements (Ugurbil et al., 2003; Uğurbil et al., 2003b; Yacoub et al., 2005; Shmuel et al., 2007).

\footnotetext{
* Corresponding author at: Center for Magnetic Resonance Research, Department of Radiology, University of Minnesota, Minneapolis, USA. Fax: + 31433884125. E-mail address: f.demartino@maastrichtuniversity.nl (F. De Martino).

${ }^{1}$ Equal contribution.
}

Taking full advantage of the high spatial specificity available at ultrahigh fields requires intrinsically higher spatial sampling in the native image (i.e. high spatial resolution). The volume of the smallest imaging unit (i.e. voxel) affects the likelihood of distinguishing activity from distinct functional units and the ability to segregate microvasculature signals in the gray matter from non-specific contributions originating from large veins. The confound introduced by "partial volume" effects (Yacoub et al., 2003) improves with increasing the image resolution (i.e. decreasing voxel volume), the latter is ultimately constrained by the intrinsic signal-to-noise and the functional contrast-to-noise ratios (SNR and fCNR, respectively). In this respect, ultrahigh fields provide advantages because of field dependent linear gains in SNR (Vaughan et al., 2001), and supralinear gains in fCNR associated with microvasculature (Yacoub et al., 2001, 2003). These combined effects in turn improve the segregation of signals originating from different anatomical substrates (e.g. microvasculature, large surface vessels, white matter), thereby permitting a significant increase in the spatial specificity (Yacoub et al., 2007, 2008; Polimeni et al., 2010) and facilitating the imaging of human brain function down to the columnar level (Yacoub et al., 2005, 2007, 2008) 
and layer level (Menon et al., 1997; Cheng et al., 2001; Harel et al., 2006; Zhao et al., 2006; Yacoub et al., 2007; Polimeni et al., 2010). Compared to spin echo fMRI, gradient echo (GE) fMRI generates much reduced power deposition and offers higher temporal efficiency, allowing for larger volume coverage within a given TR. With the exception of regions of close proximity to large vessels, where direct obfuscation by large vessel signals occur, GE fMRI at ultrahigh fields benefits from the aforementioned specificity advantages.

fMRI studies conducted at conventional magnetic field strength ( $3 \mathrm{~T}$ and below) are, most of the time, collected using voxel volumes of about 8 to $27 \mathrm{~mm}^{3}$ (e.g. 2 and $3 \mathrm{~mm}$ isotropic voxels, respectively) or even larger size, providing sufficient minimum SNR and fCNR to achieve the required functional sensitivity. Consequently, partial volume effects and the intrinsic limit of the fMRI specificity at conventional fields (Lai et al., 1993; Menon et al., 1993; Frahm et al., 1994; Kim et al., 1994; Segebarth et al., 1994; Yacoub et al., 2003; Uğurbil et al., 2003a, 2003b) constrain the spatial accuracy of the fMRI maps. Furthermore, conventional analysis of fMRI data often includes spatial smoothing with large (4 mm or more) full width at half maximum (FWHM) Gaussian kernels to reduce noise. This spatial smoothing severely limits the spatial scale of investigation for human brain function and its relation to the fine-grained neuronal and anatomical structure at conventional fields. Group averaging, when employed, further amplifies this limitation by requiring additional smoothing ( 6-8 mm FWHM) of the functional data to compensate for the variability of anatomical structures and functional to anatomical correspondence across subjects.

Despite the afore-mentioned advantages, large volume high resolution GE fMRI at $7 \mathrm{~T}$ does present technical and methodological challenges. More specifically, for single shot echo planar imaging (SS-EPI) (Mansfield, 1977), shorter acquisition times for each slice (i.e. a shorter echo train length) are needed in order to obtain images that are not excessively contaminated by distortions and/or blurring effects due to decreasing $\mathrm{T}_{2}$ and $\mathrm{T}_{2}{ }^{*}$ at $7 \mathrm{~T}$ compared to $3 \mathrm{~T}$. This challenge is amplified with increasing resolution as the echo train length is elongated commensurately with resolution. Image segmentation has been used to reduce the echo train length to alleviate this problem (McKinnon, 1993; Feinberg and Oshio, 1994; Wielopolski et al., 1995) however, this significantly increases: a) the sensitivity to physiological noise and motion (Moeller et al., 2006); b) the volume acquisition time (TR). The latter leads to prolonged scan times which would be needed to collect a sufficient amount of data in an fMRI time series. With the advent of (Wiesinger et al., 2006) multi-channel receive coils and parallel imaging methods (Sodickson and Manning, 1997; Pruessmann et al., 1999), along with improved gradient performance, many of the aforementioned technical limitations at high fields have been significantly alleviated. These developments have promised to allow increases in brain coverage for high spatial resolution applications at $7 \mathrm{~T}$ without excessive sacrifices in fMRI efficiency or temporal resolution. Despite this, to date only a few whole-brain applications have been presented at ultrahigh fields and those employed either thick slices, inter-slice gaps, or scarified temporal resolution (Bianciardi et al., 2009a, 2009b, 2009c, 2011; Poser and Norris, 2009; van der Zwaag et al., 2009a, 2009b; Poser et al., 2010), thus hampering the full benefits of $7 \mathrm{~T}$ fMRI.

Furthermore, at high magnetic fields anatomical MR images exhibit large, undesirable signal intensity variations, commonly referred to as "intensity field bias" originating from the intrinsically heterogeneous receive (and transmit) RF coil sensitivity profiles (Yang et al., 2002; Van De Moortele et al., 2009). These effects preclude the use of advanced inter-subject alignment methods (Fischl et al., 1999; Goebel et al., 2006) that rely on the accurate segmentation of individual cortical surfaces. While correction for field inhomogeneities (Duyn et al., 2007; Van De Moortele et al., 2009) and subsequent segmentation of the "unbiased" anatomical images
(Olman et al., 2010) have been presented, to date no application has demonstrated cortex-based alignment at ultrahigh fields based on such unbiased anatomical images.

Here, using improved gradient and RF hardware, along with parallel imaging methods, we present the acquisition and multivariate analysis of whole-brain high (isotropic) resolution functional data acquired at $7 \mathrm{~T}$ on healthy human volunteers during rest. The resting state of the human brain has received considerable attention in the neuroscience community for studying functional brain networks and their link to underlying anatomical connections as well as for possible clinical applications. While the notion of resting brain oscillations has been known for a long time in neurophysiology (alpha oscillations in subjects resting with eyes closed were discovered in 1930 by Hans Berger), resting state networks and in particular the so called default mode network (DMN) (Raichle et al., 2001; Greicius et al., 2003) as obtained with fMRI, are particularly interesting because of the possibility of interrogating a multitude of functional circuits simultaneously (Biswal et al., 2010). Together with the analysis of the differences in resting state spatial patterns, that have proven to be related with age and gender (Esposito et al., 2008; Biswal et al., 2010), the study of the DMN in particular has opened the possibility of using resting state paradigms in clinical applications (Greicius et al., 2004; Buckner et al., 2005; Garrity et al., 2007; Sperling et al., 2009; Fox and Greicius, 2010; Tedeschi et al., 2010). While functional connections can be studied on their own, a more powerful discrimination could be obtained from the relation of resting state networks (e.g. the DMN) with underlying anatomical structures that can be measured with anatomical and diffusion MR acquisitions (Hagmann et al., 2008; Honey et al., 2009). Due to the largely distributed nature of these networks, whole-brain measurements are essential for resting state studies. Thus far, however, such investigations have been limited to lower fields using low spatial resolutions ( $>3 \mathrm{~mm}$ isotropic), and have relied on group data analysis.

The aim of the present article is twofold. First, we demonstrate that a conventional, lower field analysis pipeline, that includes cortexbased alignment of anatomical images and multivariate data-driven analysis of the functional data, can be effectively used to process anatomical and whole-brain high-resolution functional data acquired at $7 \mathrm{~T}$. In doing so, we obtain fMRI maps of resting state networks throughout the entire brain. When analyzing the data at a resolution close to the native one, functional networks show fine-grained spatial details both at the single subject and group level. Second, in order to investigate functional and anatomical partial volume effects, and assess the impact of SNR on DMN pattern detection, we compare data acquired at different isotropic spatial resolutions $(1 \mathrm{~mm}, 1.5 \mathrm{~mm}$ and $2 \mathrm{~mm})$.

\section{Material and methods}

\section{Data acquisition}

Four subjects underwent fMRI at $7 \mathrm{~T}$ on a whole body system driven by a Siemens console using a head gradient insert operating at up to $80 \mathrm{mT} / \mathrm{m}$ with a slew rate of $333 \mathrm{~T} / \mathrm{m} / \mathrm{s}$. A head RF coil (single transmit, 16 receive channels) was used to acquire anatomical $\left(\mathrm{T}_{1}\right.$ weighted) and functional $\left(\mathrm{T}_{2}{ }^{*}\right.$ weighted BOLD) images. $\mathrm{T}_{1}$ weighted $\left(1 \mathrm{~mm}^{3}\right)$ images were acquired using a modified Magnetization Prepared Rapid Acquisition Gradient Echo (MPRAGE) sequence (Mugler and Brookman, 1990) (TR $=2500 \mathrm{ms;} \mathrm{TI}=1500 \mathrm{~ms}$; $\mathrm{TE}=3.67 \mathrm{~ms}$ ). Proton density (PD) images were also acquired together with the $\mathrm{T}_{1}$ weighted images (both acquisitions are interleaved in the modified MPRAGE sequence) and were used to minimize inhomogeneities in $\mathrm{T}_{1}$ weighted images (Van De Moortele et al., 2009). Acquisition time for anatomy was $\sim 7 \mathrm{~min}$. For resting state fMRI we obtained 3 data sets for each subject, using either $1 \mathrm{~mm}$ (85 slices; GRAPPA acceleration X4; partial Fourier 5/8) 1.5 mm (60 
slices; GRAPPA acceleration X3; partial Fourier 6/8) and $2.0 \mathrm{~mm}$ (50 slices; GRAPPA acceleration X2; partial Fourier 7/8) isotropic resolution, keeping repetition (TR) and echo (TE) times constant (2800 $\mathrm{ms}$ and $17 \mathrm{~ms}$ respectively). The full Fourier EPI readout lengths were $20.2 \mathrm{msec}, 20.9 \mathrm{msec}$, and $28.3 \mathrm{msec}$ for the $2.0 \mathrm{~mm}, 1.5 \mathrm{~mm}$, and $1.0 \mathrm{~mm}$ resolutions, respectively. With a gray matter $\mathrm{T}_{2}{ }^{*}$ of around $25 \mathrm{msec}$ (Yacoub et al., 2001) the resolution loss along the phase encode direction is minimal (Haacke et al., 1999). Each scan consisted of 210 gradient-echo echo-planar (GE-EPI) volumes and lasted $\sim 10 \mathrm{~min}$. During the scans the subjects were asked to rest motionless and awake with their eyes closed.

\section{Data analysis}

$\mathrm{T}_{1}$ weighted images were divided with PD weighted images to obtain unbiased anatomical images (Van De Moortele et al., 2009) which were then normalized to Talairach space and segmented in a semi-automated fashion to define the white matter/gray matter boundary. Individually reconstructed surfaces of left and right hemispheres were used to perform cortex-based inter-subject alignment and cortex-based independent component analyses (Goebel et al., 2006).

The functional time-series were co-registered to the individual anatomies and pre-processed using standard procedures (slice scan time correction, 3D motion correction, high-pass temporal filtering). In all time-series the motion estimates provided by the 3D motion correction procedure were limited below the voxel resolution during the scan time.

In a preliminary analysis we applied a conventional analysis pipeline for resting state fMRI time series as follows. All data sets were resampled in Talairach space at an isotropic resolution of $3 \mathrm{~mm}$ after spatial smoothing with a $6 \mathrm{~mm}$ FWHM Gaussian kernel. The individual low resolution and spatially smoothed time series were combined with the individually reconstructed cortices to extract functionally connected brain networks using cortex-based independent component analysis (cb-ICA) (Hyvarinen, 1999; Formisano et al., 2004). Self Organizing Group independent component analysis (SogICA) (Esposito et al., 2005) was used to obtain spatially consistent Independent Components (ICs) across subjects that were pooled in a voxel-level random-effects analysis to produce group component maps.

After visual inspection and manual component selection, high resolution $(1 \mathrm{~mm})$ functional masks of prototypical RSNs (e.g. the DMN) were created from the low-resolution spatially smoothed group independent component maps obtained from the $2 \mathrm{~mm}$ isotropic acquisitions. These masks were used for automatic selection of individual components obtained from the subsequent highresolution cortex based ICA analysis (Formisano et al., 2004).

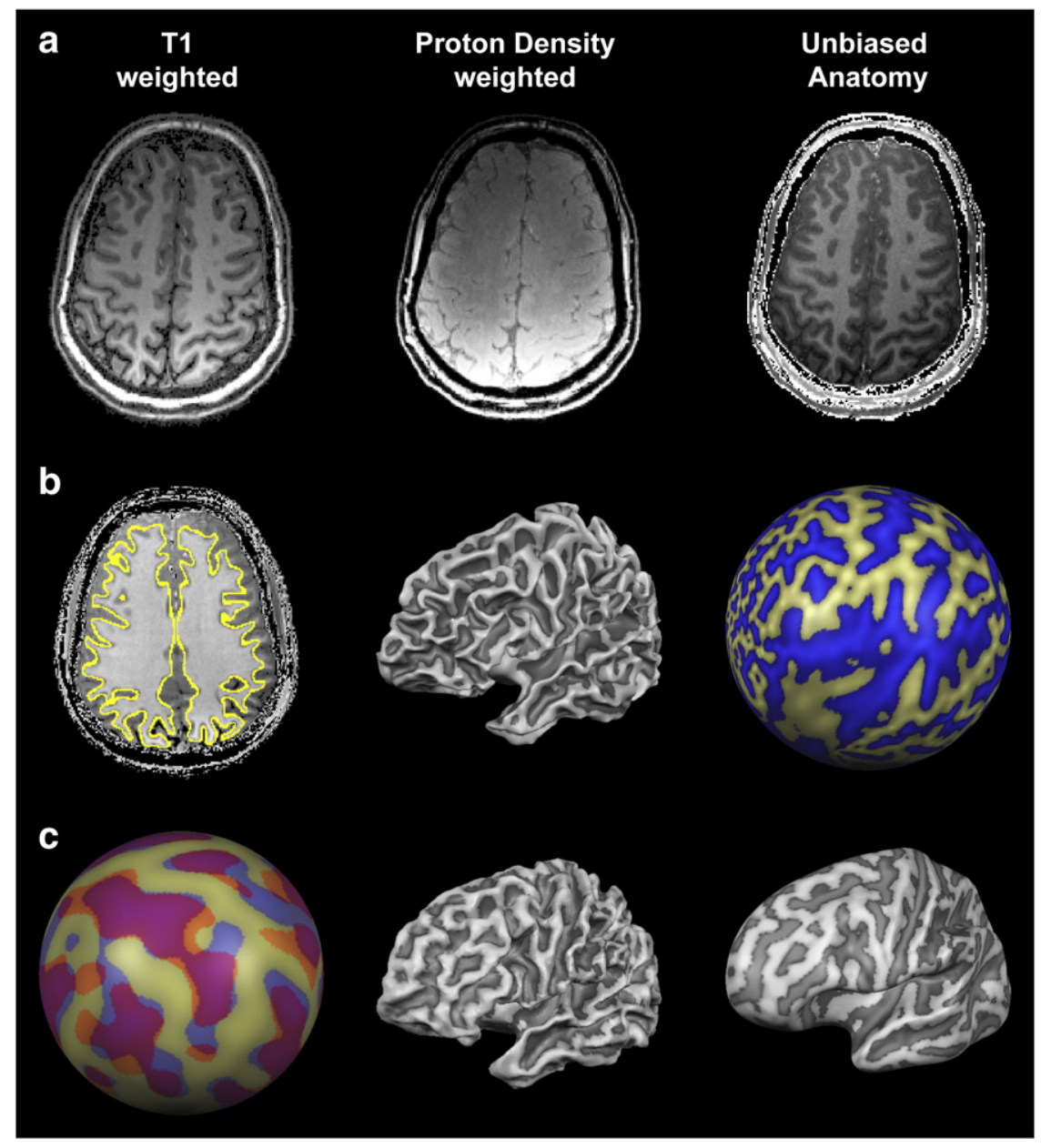

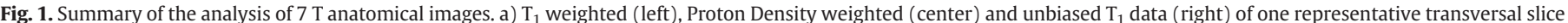

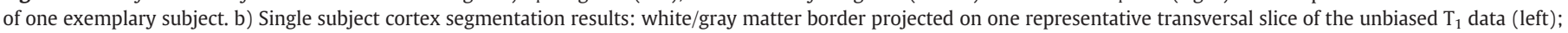

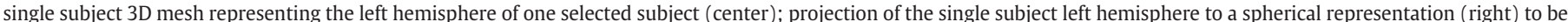

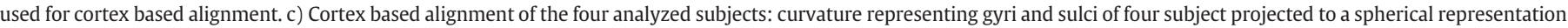

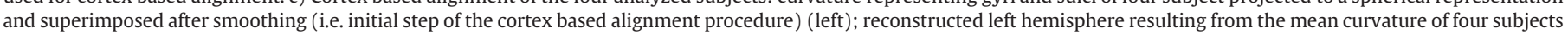
after cortex based alignment (center); inflated representation of the mean left hemisphere (right). 
In spatial ICA (commonly applied to fMRI data) the statistical samples correspond to voxel observations (spatial statistics) and "super-Gaussian" spatial components (i.e. with leptokurtic statistical distributions), which are preferentially pursued (McKeown et al., 1998; Hyvarinen et al., 2001; Calhoun et al., 2001). Therefore, in order to quantify the effects of partial volume and evaluate the functional to anatomical relationship we matched statistical samples across all acquisitions by resampling all data sets towards the highest native spatial resolution (represented by the $1 \mathrm{~mm}$ data set). Spatial differences in the results can then be interpreted as caused by differential spatial averaging in the acquisitions (e. g. more or less partial volume effects) and not as arising from the different number of statistical samples used in the analysis. While preserving spatial information was key to the overall aim of this study, all data sets were slightly spatially filtered by 2 voxels (Gaussian kernel of $\mathrm{FWHM}=2 \mathrm{~mm}$ ) after resampling at the common $1 \mathrm{~mm}$ resolution. This choice was made to homogenize in part the smoothness (i.e. the initial "gaussianity" of the data) towards the highest native spatial smoothness (represented by the $2 \mathrm{~mm}$ data set resampled to $1 \mathrm{~mm}$ ), a factor that could affect the convergence of the ICA algorithm and the quality of the resulting ICA decompositions.

The identification of components of interest (e.g. the DMN) was performed on a single subject and single run level by correlating each IC map with the previously computed group mask. High-resolution group maps were obtained by computing second level statistics ( $t$-test) in Talairach space.

To further investigate the partial volume effects within the DMN distribution and possibly identify contributions from small draining vessels in the proximity of the cortex, we used a temporal backprojection procedure. Namely, we tested whether across all subjects and voxels the regression of all concatenated individual voxels' timecourses to the concatenated individual DMN component time-courses exhibited a coherent co-activation (i.e. in phase over time with the rest of the voxels). Since the ICA decomposition is estimated up to a sign and scale factor, the individual DMN independent component time-courses were first sign adjusted to make the bulk of the spatial distribution (i.e. the portion with the most activated voxels) positive in all subjects and then standardized by transformation to temporal

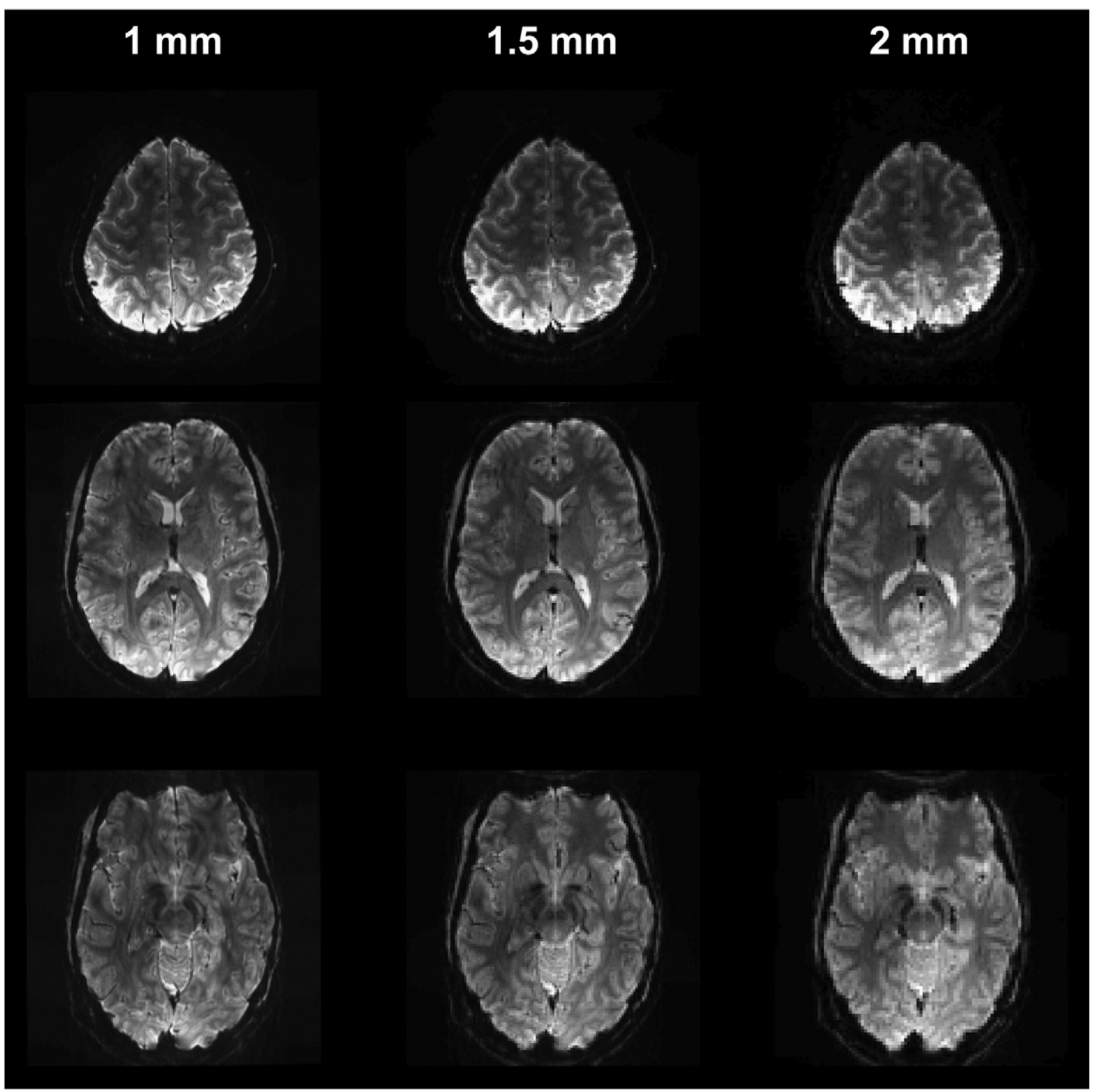

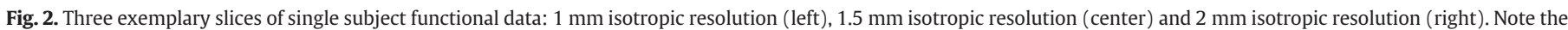
higher level of distortions due to partial volume in the frontal cortex of the $2 \mathrm{~mm}$ isotropic data (yellow arrow). 
z-scores (i.e. demeaned and scaled by their standard deviation). This way, by entering the sign-adjusted and z-transformed ICA time courses as predictors in a single subject and group general linear model (GLM) analysis (fixed effects), we obtained t-statistic maps whose sign is indicative of the relative phases of the signals and whose absolute value is indicative of the contrast-to-noise.
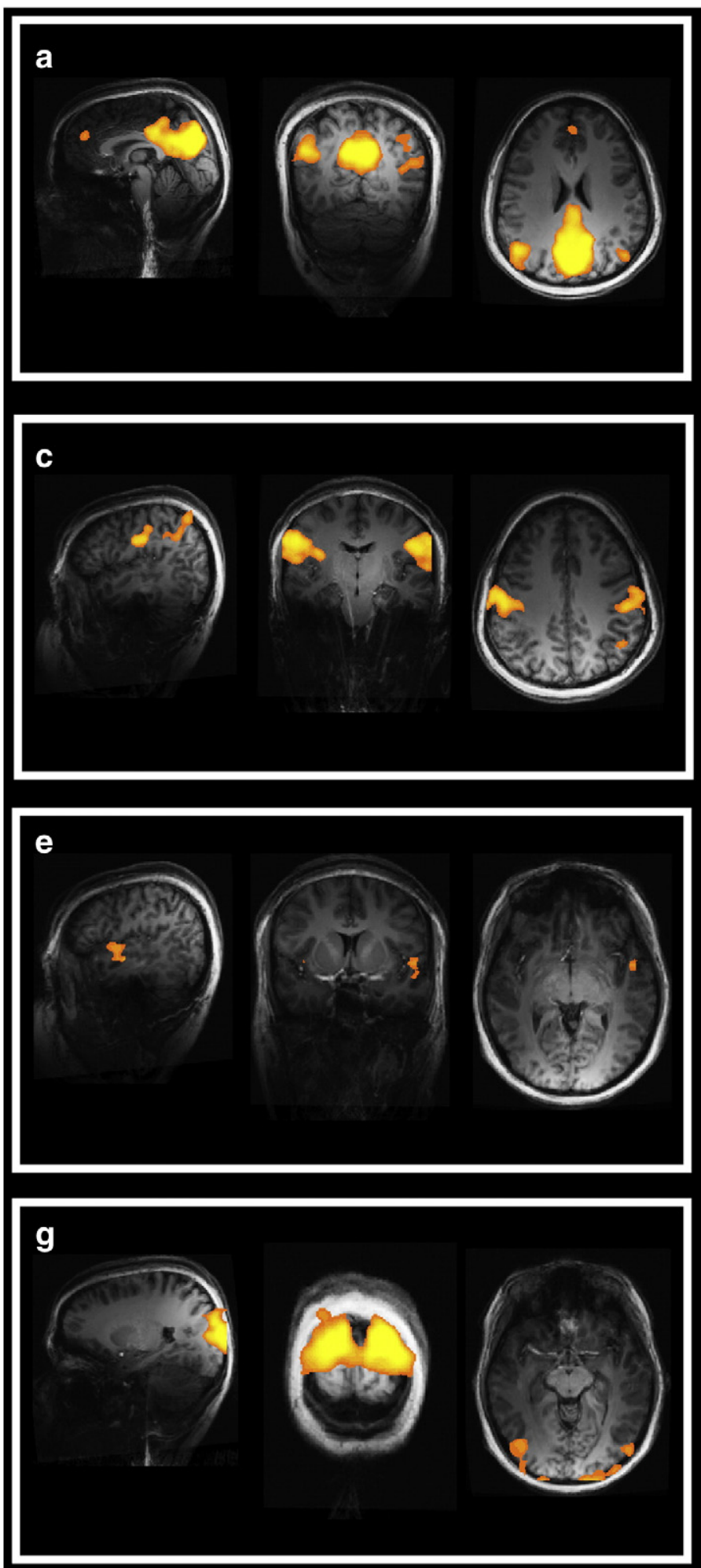

\section{Results}

Analysis of anatomical images

The results of the processing of the anatomical images $\left(T_{1}\right.$ and PD weighted) are presented in Fig. 1. Both the $T_{1}$ and PD weighted images
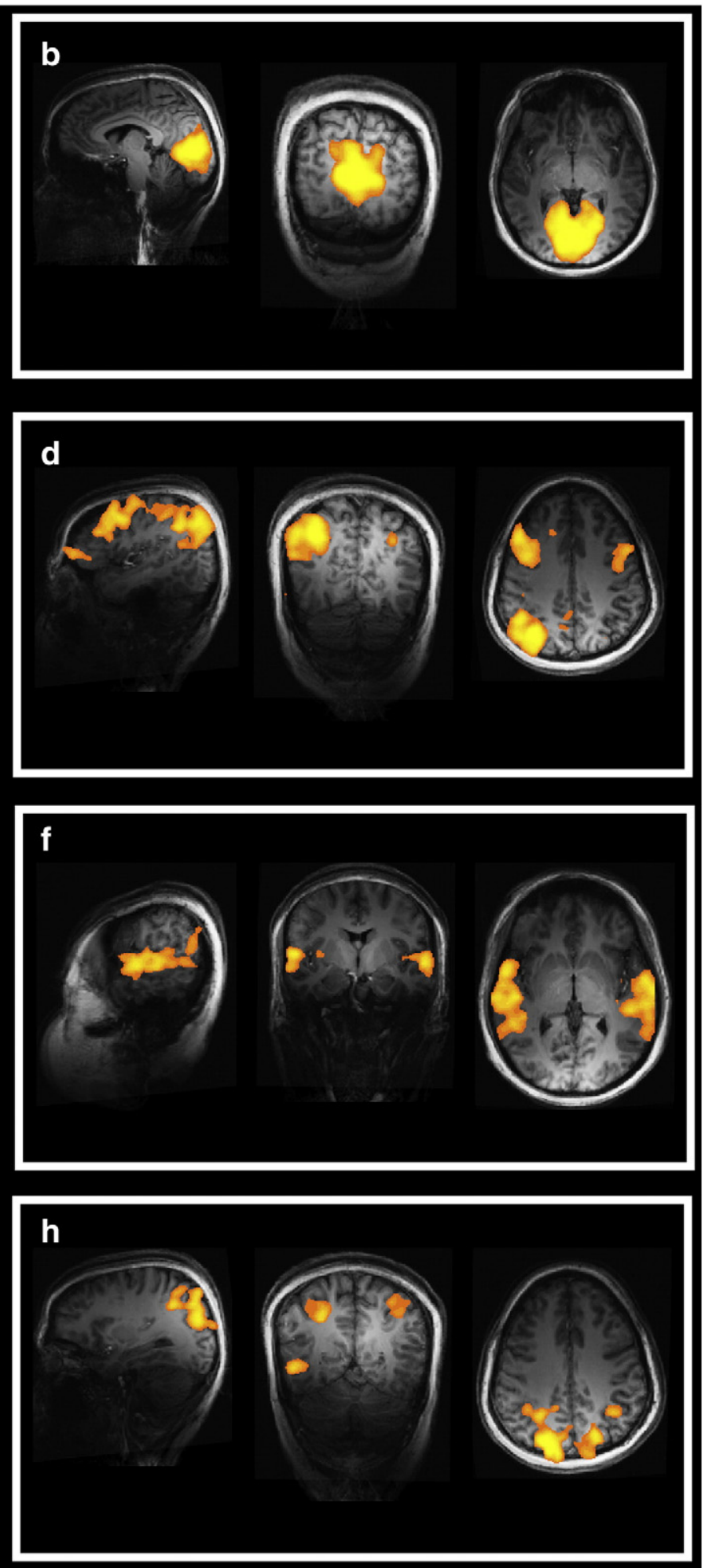

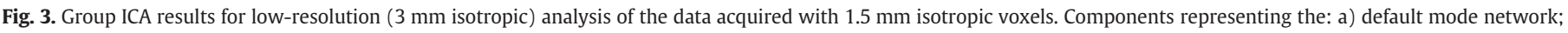

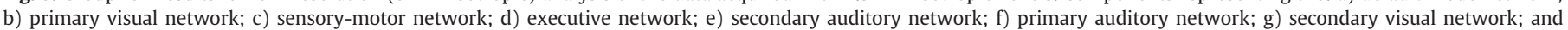
h) imagery network; are overlaid on the average anatomical $\mathrm{T}_{1}$ data. 
show characteristic inhomogeneities mostly due to the receive (and to a lesser degree the transmit) RF coil profile, which are mostly absent when $T_{1}$ weighted data are divided by the corresponding Proton Density data (Duyn et al., 2007; Van De Moortele et al., 2009) (see Fig. 1a for a representative transversal slice of one subject). Segmentation results obtained with the unbiased anatomical images are shown for one subject in Fig. 1b where the white/gray matter boundary can be seen as a yellow line (left). Fig. 1b (center) also shows the reconstructed surface representing the boundary between white and gray matter. A cortical mask was generated from the individual surfaces and was used for the analysis of the functional data. The cortical surface was further morphed to a sphere (Fig. 1b right) in order to perform inter-subject cortex-based alignment (Goebel et al., 2006) across all four subjects. Fig. 1c (left) shows the initial phase of the realignment of all subjects $(\mathrm{N}=4)$ on the cortical space. After alignment, a group surface (Fig. 1c center) was obtained from the mean cortical curvature across subjects. For each individual subject the group surface was also inflated for better visualization (Fig. 1c right).

\section{Analysis of high-resolution functional data}

Fig. 2 shows the quality of the high-resolution single shot 7 T EPI images (three transverse slices) employed for the resting state time series in one particular subject. Note the readily increased anatomical detail in the $1 \mathrm{~mm}$ data set compared to the $2 \mathrm{~mm}$ data set.

Fig. 3 shows the group results $(p=0.01)$ of the low-resolution analysis for the $1.5 \mathrm{~mm}$ isotropic data set. Components of interest were selected manually and highlight classical resting state networks (a DMN; b - primary visual network; c - motor network; $d$ - executive network; e - secondary auditory network; f - primary auditory network; g - secondary visual network; f - parietal network). The results from the same analysis on the $1 \mathrm{~mm}$ and $2 \mathrm{~mm}$ isotropic data are highly similar (apart from a small decrease in sensitivity noticeable for the auditory components in the $1 \mathrm{~mm}$ data likely due to the higher levels of BOLD signal saturation caused by the higher acoustic noise) and are reported in Supplementary Figs. 1 and 2. This demonstrates that $7 \mathrm{~T}$ resting state fMRI acquisitions can provide with expected resting state patterns.

Fig. 4a shows, overlaid on the averaged $T_{1}$ anatomical data, the template for the DMN (sagittal, coronal and transversal views) obtained from the group ICA of the $2 \mathrm{~mm}$ isotropic data resampled at low $(3 \mathrm{~mm})$ resolution in Talairach space and further smoothed with a Gaussian kernel of 2 voxels ( $6 \mathrm{~mm}$ ) FWHM. The group component map shows a pattern typically expected for the DMN comprising the anterior cingulated cortex (ACC), the precuneus (PreCu) and bi-lateral parietal cortex (ParC). This template was used to select the DMN component in ICA analyses of all acquired data $(1 \mathrm{~mm} ; 1.5 \mathrm{~mm}$ and $2 \mathrm{~mm}$ isotropic time series) after they were resampled to $1 \mathrm{~mm}$ isotropic resolution in

a

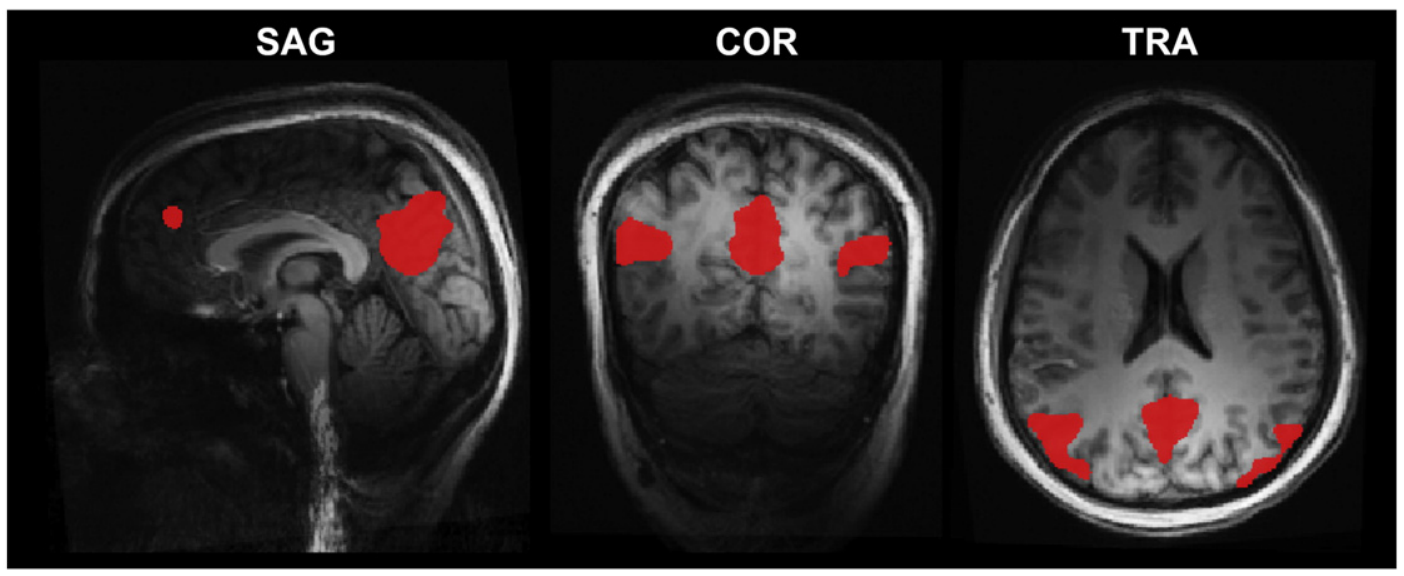

b

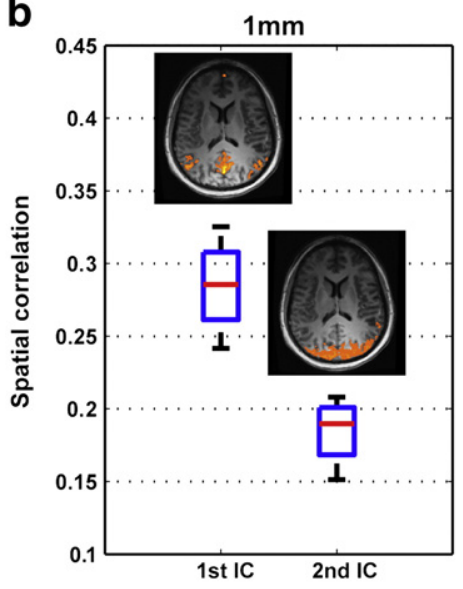

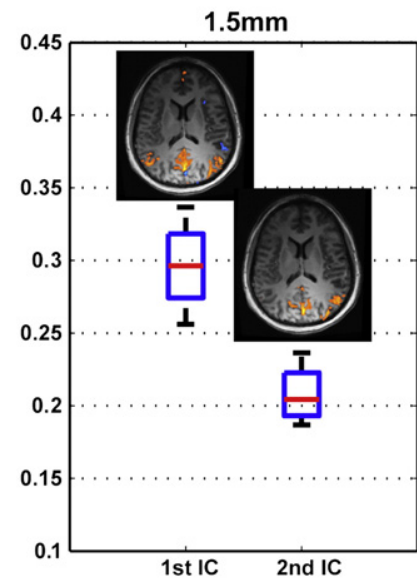

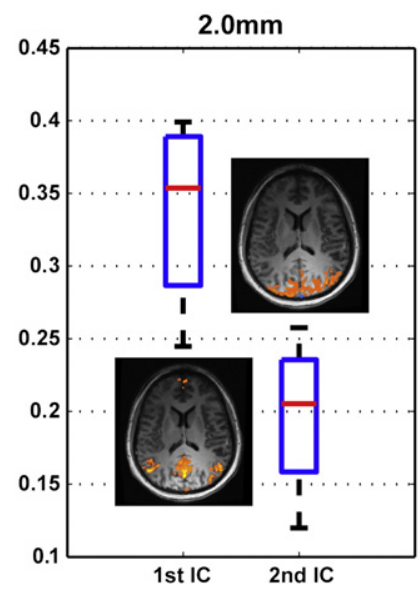

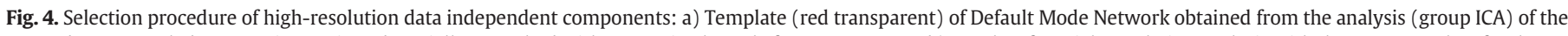

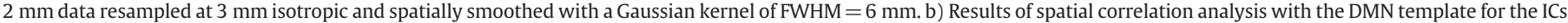

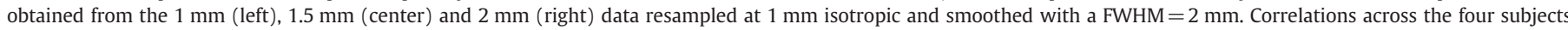

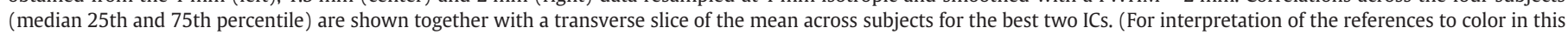
figure legend, the reader is referred to the web version of this article.) 


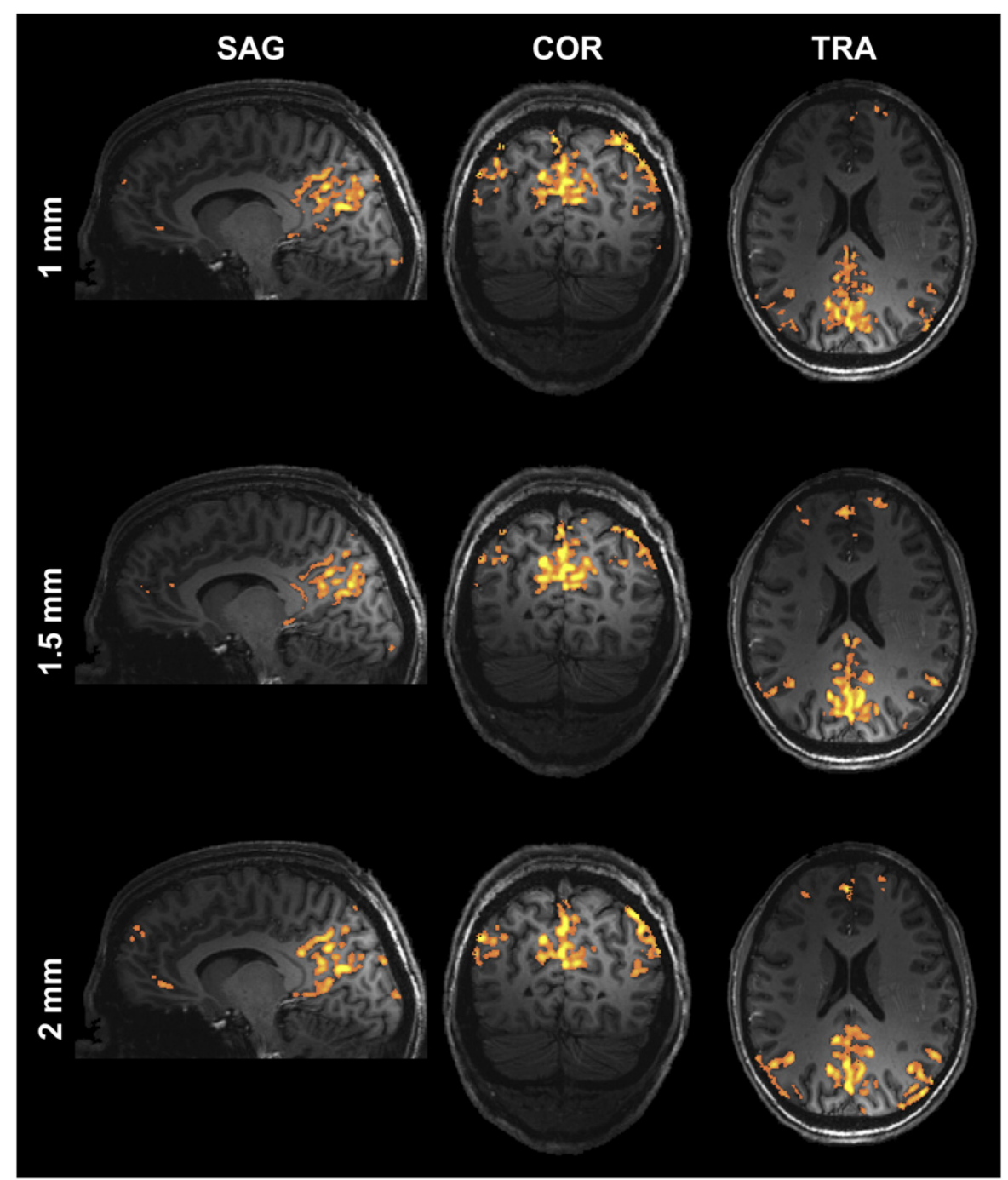

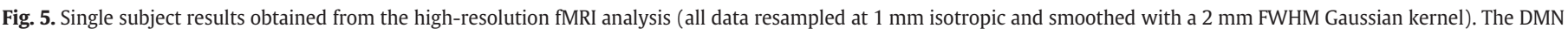

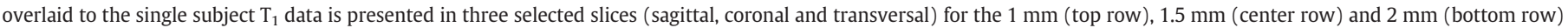
data.

Talairach space and slightly smoothed with a 2 voxel ( $2 \mathrm{~mm})$ FWHM Gaussian kernel. Fig. 4b shows the results of the spatial correlation analysis. The correlation with the template for the first and second most correlated ICs to the DMN template is reported for all data sets together with one transversal slice of their group maps. The box plots represent the variability (minimum, maximum, median and 25th and 75th percentiles) across all subjects $(\mathrm{N}=4)$. For all resolutions we observed a significant difference (paired t-test) $(1 \mathrm{~mm} p=0.0032 ; 1.5 \mathrm{~mm}$ $p=0.0041 ; 2 \mathrm{~mm} p=0.02$ ) between the first and second best ranked component indicating that the DMN component was reliably and selectively detected with a high level of accuracy at the single subject level.

The high resolution DMN distribution in one particular subject is reported in Fig. 5 (single subject maps are descriptively thresholded at $z$-value $=2$, see, e. g. McKeown et al., 1998). For all resolutions, the DMN component maps correspond to the expected network distribution, encompassing PreCu, bilateral ParC and the ACC as well as a much higher degree of functional correspondence with the subject's anatomy than what was observed in the low-resolution analysis and template reported in Figs. 3 and 4 (e.g. here, activated voxels reside mostly within the gray matter). It has to be noted that at the single subject level the analysis of not spatially smoothed high resolution data resulted in smaller activation extent of the ACC.
We investigated the partial volume effects using a temporal backprojection procedure within the GLM framework. Single subject and group t-statistic maps are indicative of the relative phases of the signals in different regions. Single subject results (FDR corrected threshold of $q=0.05$ ) for the $1.5 \mathrm{~mm}$ data are presented in Fig. 6 (zoomed in portions of the sagittal and transversal views). The map shows areas with a clear inversion of phase in the signal fluctuations (blue regions in Fig. 6a (top) super imposed on a grayscale inverted GE-EPI image). These regions coincide with areas of hyper intensity in the inverted GE-EPI images (Fig. 6a bottom), indicating a likely venous contribution to these counter phase signals. In Fig. $6 \mathrm{~b}$, we report a single subject time course from two regions extracted from the $1.5 \mathrm{~mm}$ acquisitions within the in-phase (red) and inverted phase (blue) activation areas. Even when looking at the full distribution of tvalues across all subjects, the $1 \mathrm{~mm}$ and $1.5 \mathrm{~mm}$ acquisitions show areas within the DMN that have a clear inversion of phase in the signal fluctuations (blue regions in the $1 \mathrm{~mm}$ and $1.5 \mathrm{~mm}$ maps in Fig. 7). The persistence of this result across subjects indicates spatial consistency of the phenomenon underlying this partial volume effect.

To investigate further how partial voluming would affect the functional to anatomical correspondence, we evaluated the possible relationship between the white/gray matter structural contrast and the DMN functional activity distribution within the precuneus, since 
a

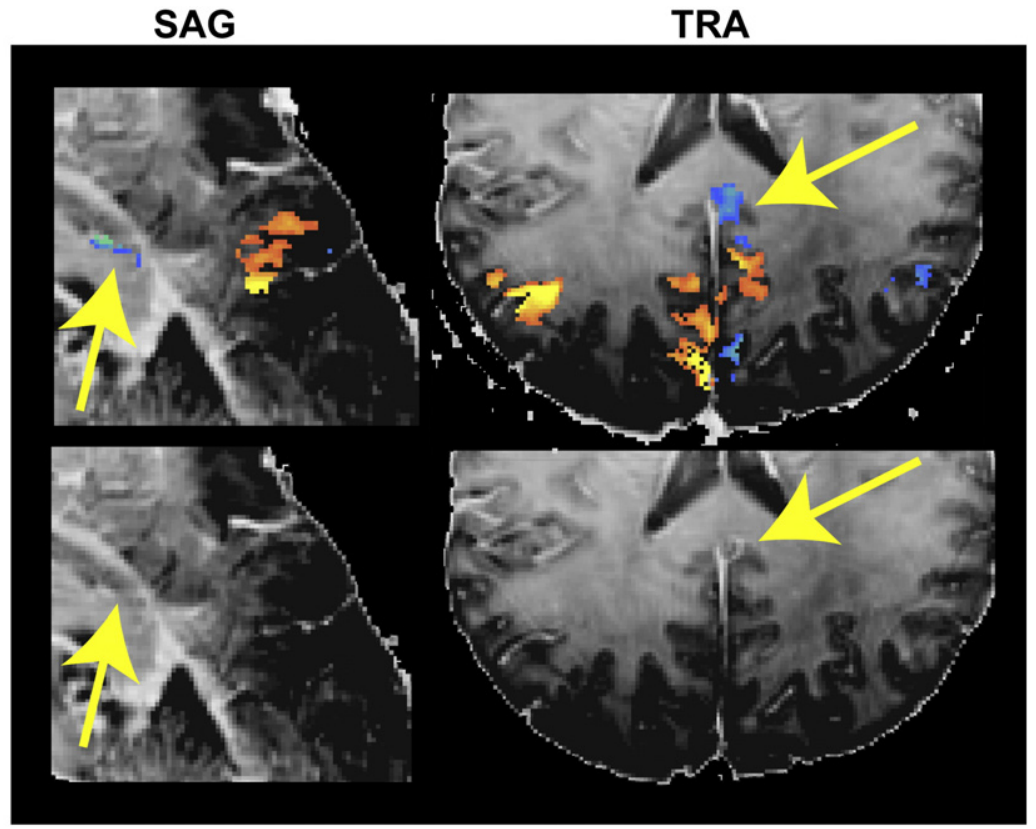

b

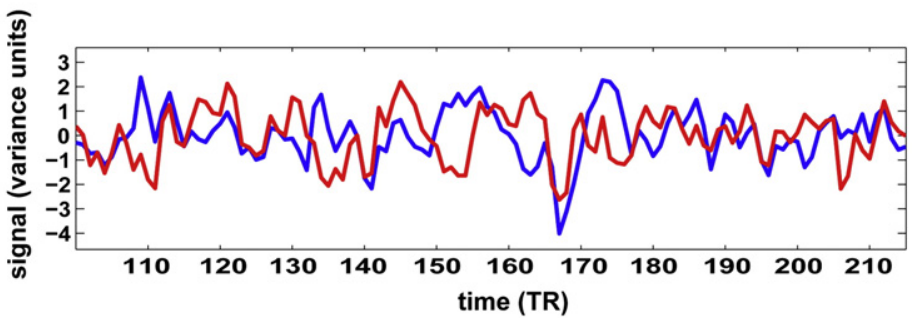

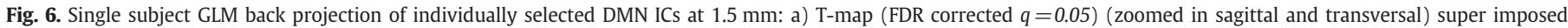

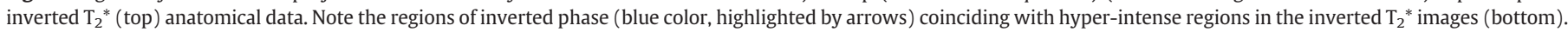

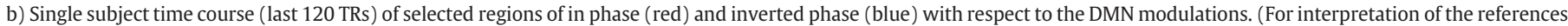
to color in this figure legend, the reader is referred to the web version of this article.)

this is the most consistent and extended node of the DMN. To generalize this effect across subjects, this analysis was performed using anatomical and functional group averaged maps across all four subjects. For the anatomical information we used the unbiased $\mathrm{T}_{1}$ image, where gray and white matter pixels have lower and higher intensity values, respectively. For the functional information we used group t-statistic maps resulting from the GLM back-projection (see above) thresholded at $p=0.05$ (uncorrected) in a rectangular box defined in such a way to overlap with most of the precuneus part of the DMN activity and include a significantly high and balanced number of both white and gray matter voxels. This way, the count of "more white matter" and "more gray matter" voxels could be related to the count of "more active" and "less active" DMN voxels against the normalized average $T_{1}$ signal intensities in superimposed histograms. The use of an uncorrected p-value allowed us to maximize the differential sensitivity of the three acquisitions in those regions that were more exposed to partial volume effects and thus with less functional CNR. Fig. 8a shows histograms representing the number of voxels in the selected precuneus region as a function of their gray scale value in the unbiased anatomical image. For each anatomical gray value level the total number of voxels is shown (gray line) as well as the number of activated voxels ( $p<0.05$ uncorrected) in the $1 \mathrm{~mm}$ (red line), $1.5 \mathrm{~mm}$ (blue line) and $2 \mathrm{~mm}$ (green line) data. Despite averaging information across subjects, two peaks, corresponding to gray matter (gray scale value 100 ) and white matter (gray scale value 140 ), are easily identified (gray values for anatomical data expressed in arbitrary units). As expected, due to the higher fCNR, a greater number of activated voxels are detected at the lower resolutions. It is also noticeable that the $2 \mathrm{~mm}$ data have a slight increase in the number of activated voxels in the white matter range that we attributed to partial voluming. This latter effect is more evident when the histograms are normalized to the total number of activated voxels (Fig. 8b). Here, the curves show that the $2 \mathrm{~mm}$ data have a relatively higher number of activated voxels in the white matter region compared to the $1 \mathrm{~mm}$ and $1.5 \mathrm{~mm}$ data. To further highlight this effect we also computed the ratio between the $2 \mathrm{~mm}$ and $1 \mathrm{~mm}$ normalized histograms (red in Fig. 8c) and between the $2 \mathrm{~mm}$ and $1.5 \mathrm{~mm}$ normalized histograms (blue in Fig. 8c) through the gray matter and white matter range (gray scale values between 75 and 150).

Group ( $\mathrm{N}=4)$ ICA maps obtained by averaging the individually identified DMN components are presented in Fig. 9 (sagittal, coronal and transversal; maps were computed using a second level statistical analysis and thresholded at $p=0.05$ ) for all acquisitions. Even across multiple subjects the DMN obtained from high-resolution acquisitions (1 $\mathrm{mm}$ isotropic) preserves the expected pattern of activation including the ACC, PreCu and bilateral parietal cortex. Note the similarity with the single subject DMN maps presented in Fig. 5.

Fig. 10 shows the group results obtained for two other typical resting state networks (maps were computed using a second level statistical analysis and thresholded at $p=0.05$ ). Selection of individual ICs followed the same procedure used for the DMN (i.e. spatial correlation with a template obtained from the low-resolution analysis of the $6 \mathrm{~mm}$ spatially smoothed $2 \mathrm{~mm}$ isotropic data set). In Fig. 10a 


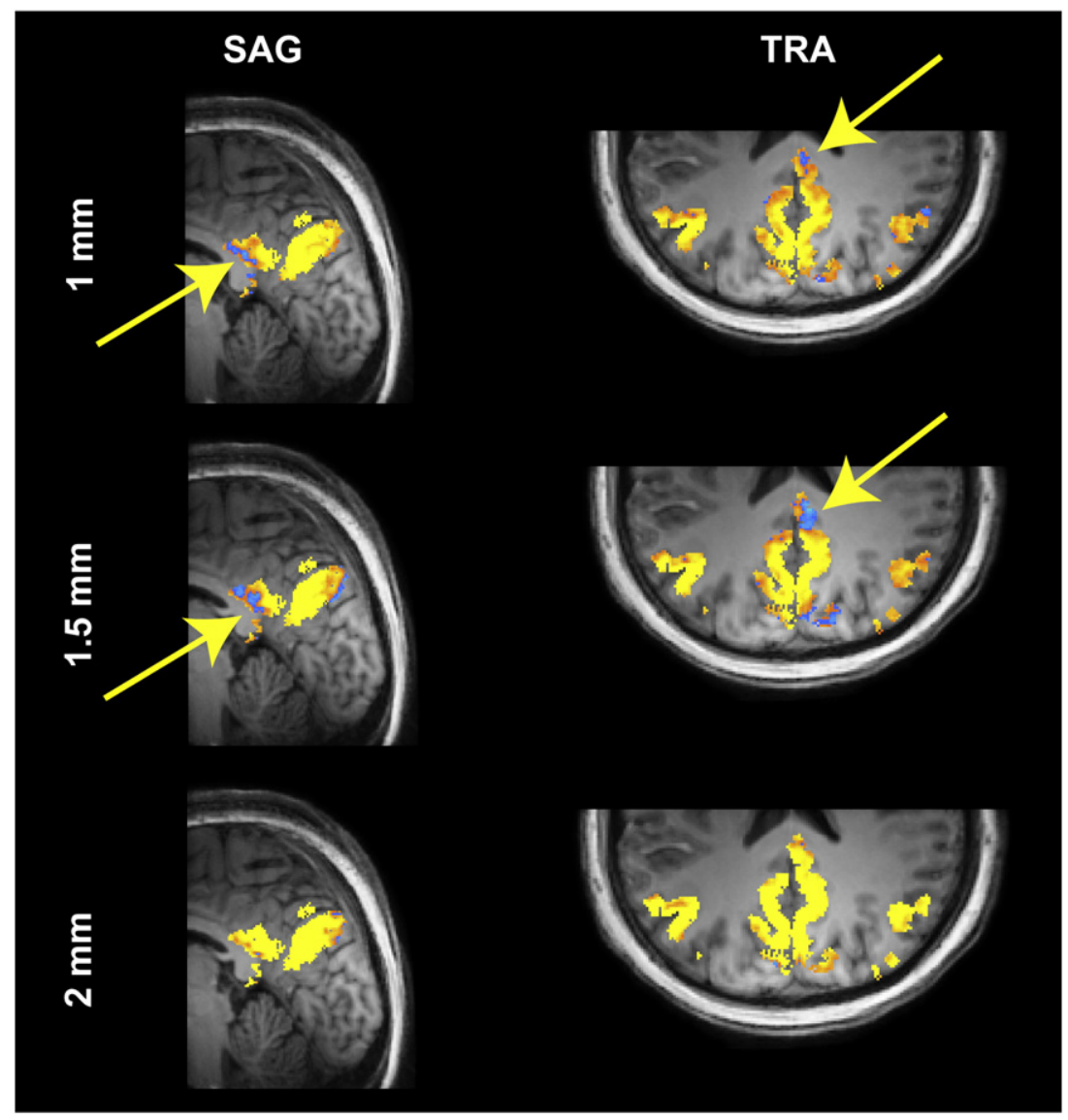

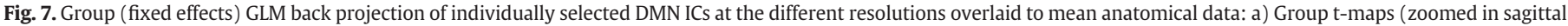

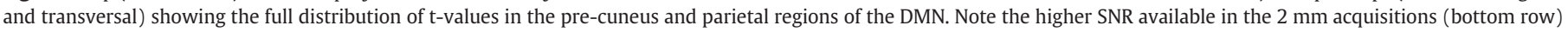

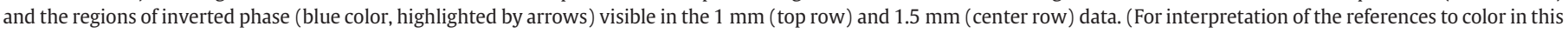
figure legend, the reader is referred to the web version of this article.)

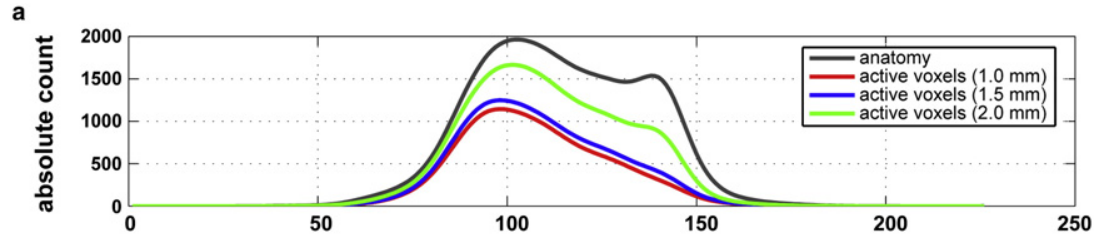

b
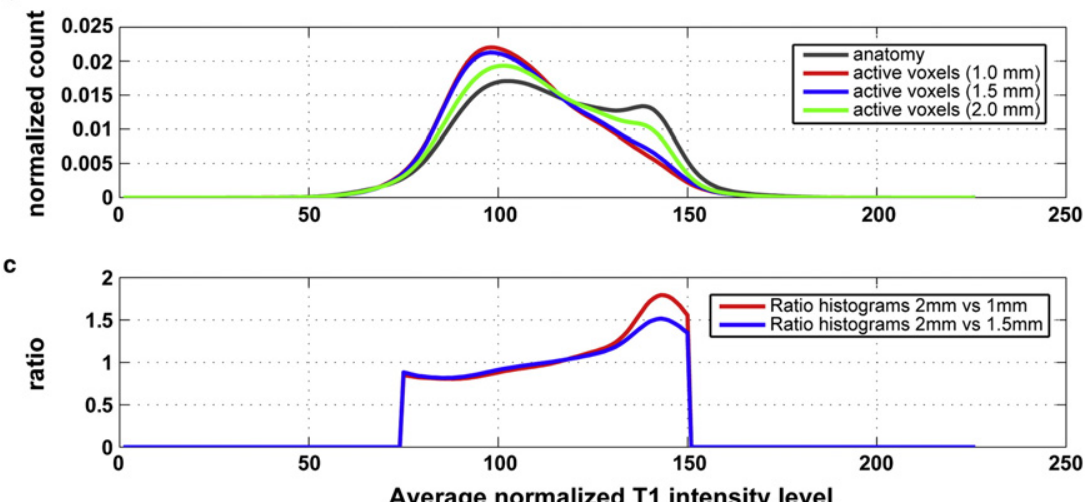

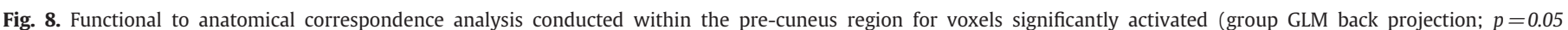

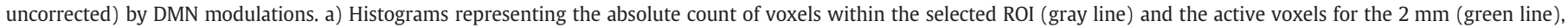

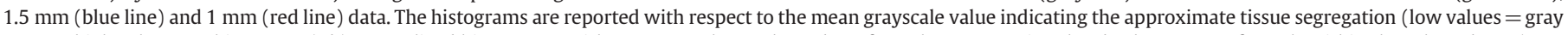

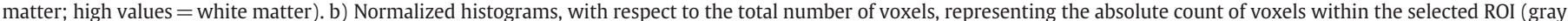

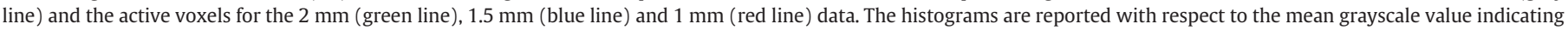

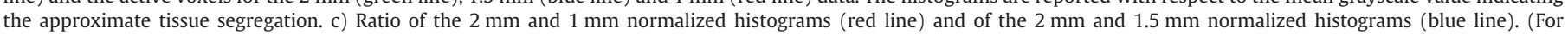
interpretation of the references to color in this figure legend, the reader is referred to the web version of this article.) 


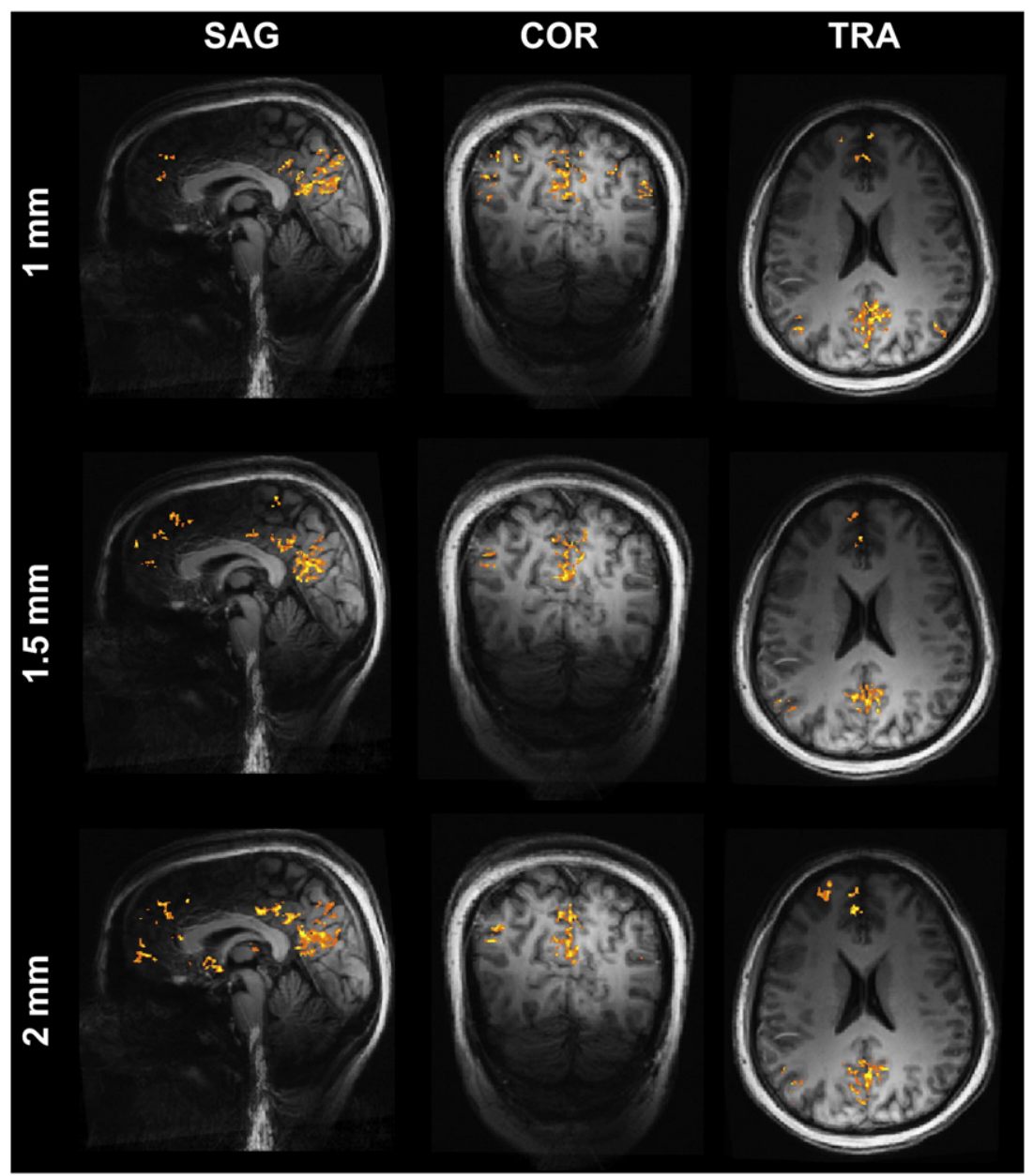

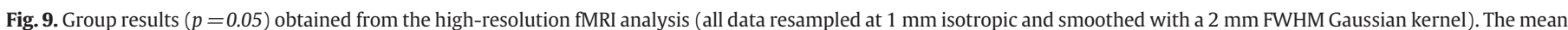

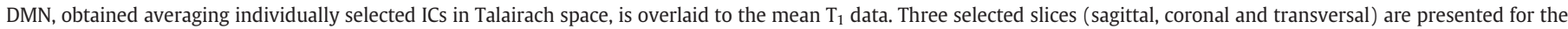
$1 \mathrm{~mm}$ (top row), $1.5 \mathrm{~mm}$ (center row) and $2 \mathrm{~mm}$ (bottom row) data.

the primary visual network is presented (one selected transversal slice) for all resolutions. While little difference can be noted between the $1.5 \mathrm{~mm}$ and $2 \mathrm{~mm}$ data, the $1 \mathrm{~mm}$ data highlight a smaller network of visual areas indicating a possibly reduced signal-to-noise ratio at this spatial resolution. In Fig. 10b a network activating bilateral somato-sensory cortices is presented (one selected transversal slice). At the group level, the $1 \mathrm{~mm}$ data fail to highlight regions around the central sulcus indicating that the $1 \mathrm{~mm}$ acquisition may suffer from a reduced signal-to-noise ratio. This effect is more visible when the maps are projected on the mean cortical reconstruction of the four subjects (obtained by averaging the curvature in the cortex based realigned space) (see Fig. 10c).

\section{Discussion}

High-resolution fMRI exploits the benefits of high fields (Yacoub et al., 2001, 2005) since lower resolutions tend to be dominated by physiological noise, and therefore limit the possible gains in functional sensitivity (Triantafyllou et al., 2005; Yacoub et al., 2005). Reciprocally, increases in the specificity of the signals at high fields can exploit these higher spatial resolutions because of the reduction in partial volume effects between micro-vasculature and large vessels or between gray and white matter, facilitating the interpretation of functional maps with respect to the underlying neuronal activity.

With these premises, we have investigated the feasibility of whole brain high-resolution functional brain imaging at $7 \mathrm{~T}$ using GE EPI and parallel imaging. We have used a resting state protocol, which is a compelling application that requires whole brain coverage because of the intrinsic whole-brain nature of resting state networks.

We aimed at localizing fine-grained spatial effects within networks that can only be apprehended at high spatial resolutions. More specifically, we investigated the effect of higher resolutions on partial voluming by reducing the acquired voxel volume from $8 \mathrm{~mm}^{3}$ to $3.375 \mathrm{~mm}^{3}$ and $1 \mathrm{~mm}^{3}$.

Multiple imaging parameters can change when different spatial resolutions are used, which can potentially impact functional data analysis (i.e. ICA). We therefore chose to match the TR, TE, and acquisition time through all series - keeping the total number of images and fMRI contrast the same in order to fairly compare the functional information present in multi-resolution data. The repetition time ( $\mathrm{TR}=2800 \mathrm{~ms}$ ) was optimized for the high-resolution acquisitions ( $1 \mathrm{~mm}$ isotropic) and then used for all other acquisitions (1.5 mm isotropic and $2 \mathrm{~mm}$ isotropic) in order to maintain the number of samples used in the analysis constant. Even though this TR was not optimized for the lower resolution acquisition, it clearly provided sufficient sensitivity to detect typical resting state networks in the $2 \mathrm{~mm}$ data, as can be seen in Figs. 4, 8, 9 and in Supplementary Fig. 2 for single subject and group results. We do not expect that a shorter TR would have altered the lack of information demonstrated in the $2 \mathrm{~mm}$ data, given the fact that partial voluming effects were responsible for this observation and that the $2 \mathrm{~mm}$ data had, in any case, a higher functional sensitivity. It should also be noted that the lowest spatial resolution utilized in this study ( $8 \mathrm{~mm}^{3}$ voxel size) was still significantly smaller than what is commonly used at $3 \mathrm{~T}\left(27 \mathrm{~mm}^{3}\right.$ 


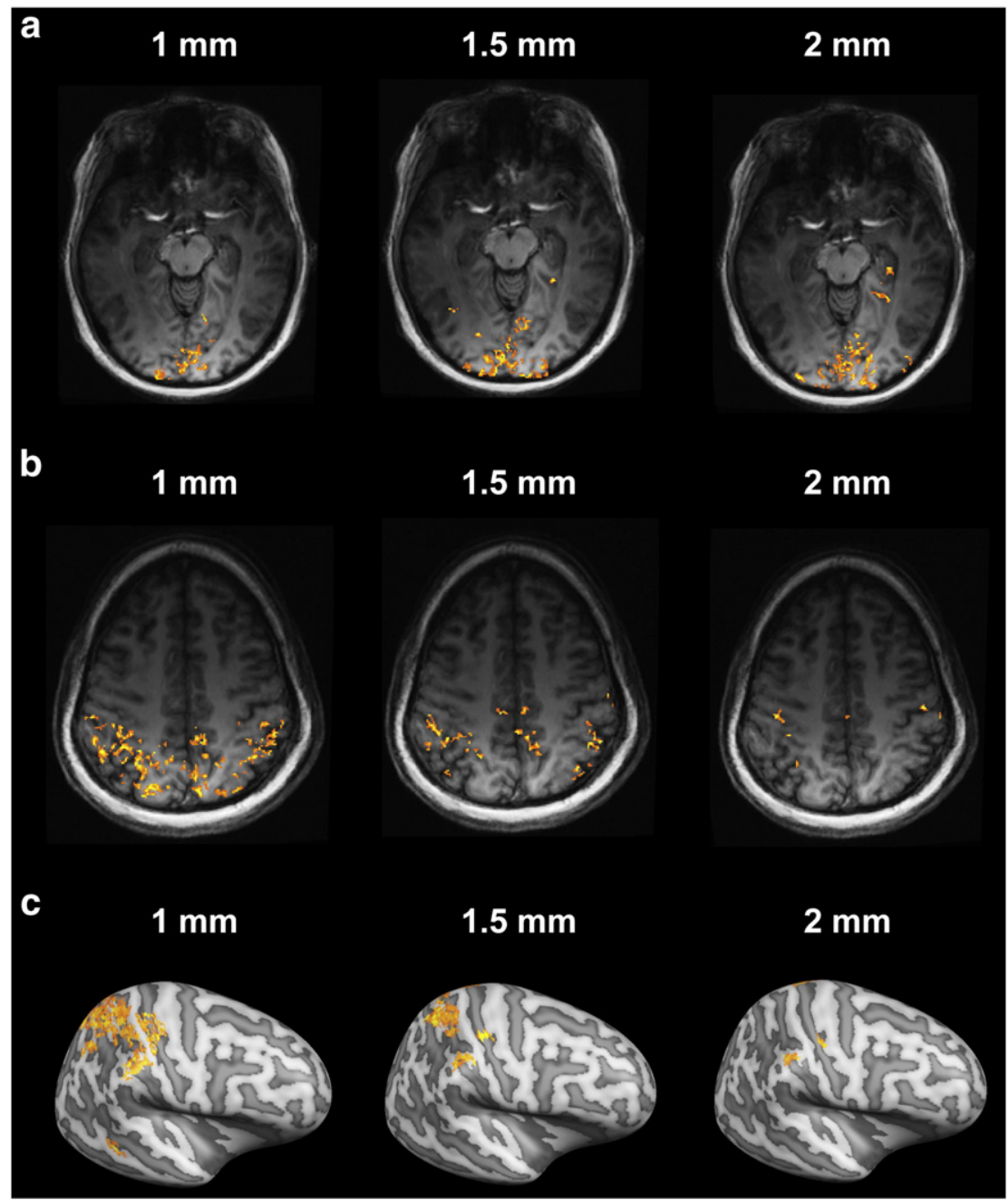

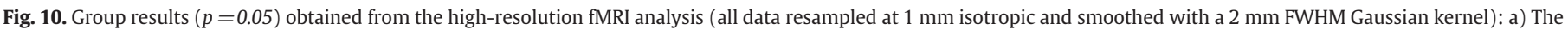

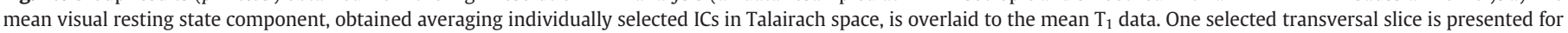

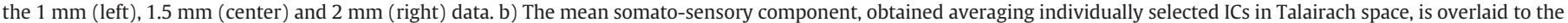

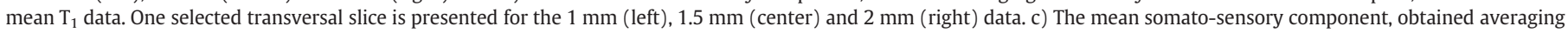

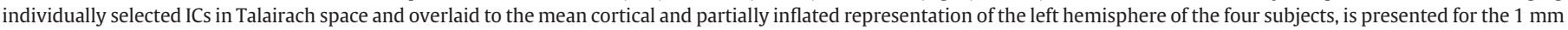
(left), $1.5 \mathrm{~mm}$ (center) and $2 \mathrm{~mm}$ (right) data.

voxel size). One could anticipate that expanding the comparison up to this larger voxel size would result in even more pronounced partial voluming effects.

All fMRI patterns presented and compared in this study were obtained in a fully data-driven fashion using cortex-based ICA. The quality of the unbiased anatomical images, highlighted by the possibility of performing inter-subject cortical realignment (see Fig. 1), allowed for the definition of the cortical manifold on which the analysis was performed. While ICA has become the method of choice for voxel-level distributed analysis of whole brain functional connectivity, it is noteworthy that equalizing the number of voxels in the ICA analysis ensured that all differences observed in the component maps were principally due to physical characteristics (e. g. native spatial resolution and partial volume) and not to a different behavior of the ICA algorithm related to a changing statistical structure of the data.

A conventional $3 \mathrm{~T}$ pipeline analysis that comprises low resolution spatial resampling, and heavy spatial smoothing, allowed the extraction of many typical resting state components (Damoiseaux et al., 2006) across subjects (see Fig. 3 and Supplementary Figs. 1 and 2 ), with the expected widespread non-specific functional distributions. Furthermore we did not detect global effects in the spatial distribution of the resting state functional networks. These effects might be detected with a higher temporal sampling (Feinberg et al., 2010) instead of or in addition to the higher spatial sampling as adopted here. If higher temporal resolutions are needed, recent promising developments in parallel imaging and pulse sequence design allow for considerably shorter TRs while preserving conventional resolution and volume coverage (Moeller et al., 2010; Feinberg et al., 2010).

Our results show that in order to investigate fine-grained spatial effects in typical resting state networks, pre-processing and analysis have to be adapted in order to take full advantage of high resolution acquisitions. For this reason all data sets were also analyzed after resampling at a resolution of $1 \mathrm{~mm}$ isotropic in Talairach space.

The results of this analysis show that even at high resolution and with single subject DMN maps, data obtained at $7 \mathrm{~T}$ are not limited by contrast-to-noise despite a reduction in voxel volume by a factor of three or more when compared to conventional $3 \mathrm{~T}$ acquisitions (see Fig. 4) (Yacoub et al., 2001). Even at the single subject level (Fig. 5) the maps obtained from high-resolution acquisitions show the typical network distribution of co-activation, with spots in the anterior cingulated cortex, precuneus and bilateral parietal cortex that characterize the DMN. Compared to typical results obtained at 
conventional fields (3 $\mathrm{T}$ ) and using conventional preprocessing (see Fig. 3 and Supplementary Figs. 1 and 2), the high-resolution DMN shows a high degree of functional to anatomical correspondence with activation well localized to the individual gray matter volume. Even when computing average maps across four subjects (see Fig. 8), the high-resolution DMN preserves its typical activation pattern indicating that the underlying network of areas is reliable across subjects without the need for substantial spatial smoothing (as is typically done at lower fields) to increase sensitivity and functional correspondence across subjects. It has to be noted that compared to conventional results obtained at lower field strengths the DMN as highlighted here shows a smaller activation spot in the ACC. This effect is noticeable when the DMN is obtained from data resampled close to the native resolution and with only moderate smoothing (see e.g. Fig. 4 compared to low resolution results reported in Fig. 3). This can be explained by reduced signal to noise ratios in frontal regions in the high resolution acquisitions.

We used the DMN as a case study to investigate partial voluming and potential losses of information or specificity at the different resolutions. In particular, we have focused our analysis on the precuneus, which previous $3 \mathrm{~T}$ studies have indicated as a possible marker for functional classification in several cognitive disorders (Greicius et al., 2004; Buckner et al., 2005; Garrity et al., 2007; Sperling et al., 2009; Fox and Greicius, 2010) and has been highlighted as a "hub" for functional and anatomical connections (Hagmann et al., 2008; Honey et al., 2009). Several compact clusters of areas within the precuneus show, in both single subjects (see e.g. Fig. 6) and (consistently across all subjects) at the group level (Fig. 7), BOLD signals that are in counter phase with the main bulk of activity for relatively long intervals of their time course. This effect was observed in the proximity of large draining vessels as indicated by the hyper intense values in the inverted $\mathrm{T}_{2}{ }^{*}$ images. A similar effect has been already observed at the periphery of the visual cortex in previous high-resolution activation studies with only partial brain coverage (Bianciardi et al., 2011). While the effects of large vessels are reduced at high magnetic fields, these effects still persist and can be detrimental to the interpretation of functional signals (Harel et al., 2006; Yacoub et al., 2007). Furthermore, the data presented here do not have the advantage of reflecting either known spatial organizations of functional networks (i.e. cortical columns) or a differential activation paradigm (i.e. right eye versus left eye) to suppress or distinguish non-specific functional signals in space from those that are more functionally relevant.

A more detailed analysis of the anatomical location of activated $(p=0.05)$ voxels (Fig. 8 ) shows an overall advantage (i.e. more active voxels) in signal-to-noise ratio for the $2 \mathrm{~mm}$ acquisition (Fig. 8a) due to larger voxel volume and lower acceleration (GRAPPA) factor (Lütcke et al., 2006). But, relative to the total number of activated voxels, the high-resolution data $(1 \mathrm{~mm}$ and $1.5 \mathrm{~mm})$ show a larger number of active voxels in the gray matter range of average normalized $\mathrm{T}_{1}$ image intensity and a lower number of active voxels in the white matter range compared to the $2 \mathrm{~mm}$ data (Figs. $8 \mathrm{~b}$ and c). These results indicate that the $1 \mathrm{~mm}$ and $1.5 \mathrm{~mm}$ activations are better localized to the gray matter and suffer less from partial volume effects.

Using the same procedure followed for the DMN we selected single subject resting state networks in the visual and somato-sensory cortices. Group maps were obtained by averaging the single subject network distributions in the common anatomical space (Talairach space). The results shown in Fig. 9 indicate that, while the visual resting state network could be reliably detected at the group level at all resolutions, the lower SNR affected the results for the somatosensory network in the higher resolutions $(1 \mathrm{~mm})$ data sets.

While $1 \mathrm{~mm}$ and smaller voxels are necessary for applications that focus on fine grained structures (e.g. columns or laminar functional analysis) (Yacoub et al., 2007, 2008; Polimeni et al., 2010), our results suggests that, for whole-brain applications that focus on 'largely distributed' activated networks such as resting state networks, a resolution of $1.5 \mathrm{~mm}$ isotropic may offer a good compromise between partial volume and signal-to-noise ratios. However, with more optimized RF coils and parallel imaging performance, providing even higher SNRs, higher resolutions over the entire brain may be achieved without significant compromises in functional sensitivity.

One possible limitation of the present data is the lack of on-line physiological measurements. Collecting respiration data is often suggested in resting-state fMRI studies to remove the contribution of respiration-related signal changes from BOLD signal oscillations of neural origin (Birn et al., 2006). However, it has also been reported that ICA is able to separate respiration-related changes in most cases (Birn et al., 2008) and components identified as typical resting-state networks were always verified and evaluated with respect to the individual anatomy. Furthermore it has been previously shown in a $7 \mathrm{~T}$ resting-state and activation fMRI study (Bianciardi et al., 2009a, 2009b) that after removal of low frequency drifts due to head motion or resonance frequency, the largest portion of signal variance in gray matter voxels is mainly explained by thermal noise and spontaneous activity while only small portions of signal variance can be explained by respiration or cardiac effects.

\section{Conclusions}

Ultrahigh fields offer improved sensitivity and specificity for fMRI applications, facilitating the acquisition of higher resolution images and allowing for a better understanding of intrinsic properties of functional networks. By capitalizing on technical advancements in MR imaging, we demonstrated that high-resolution capabilities of high fields can be extended to the entire brain for fMRI applications. As such, we acquired and analyzed high-resolution whole brain fMRI data using a resting state paradigm. Our results suggest that the increased contrast to noise ratio at $7 \mathrm{~T}$ allows for studying the distribution of spontaneous BOLD fluctuations within functionally connected networks in single subjects, using voxel volumes of 3 to 20 times smaller than what is conventionally used at $3 \mathrm{~T}$ without the need for extensive spatial smoothing. We have shown that despite the large extent of functional networks (i.e. DMN), high-resolution functional maps depict significantly less partial volume effects and more distinct spatial features, allowing for a better localization and understanding of the activated networks.

Supplementary materials related to this article can be found online at doi:10.1016/j.neuroimage.2011.05.008.

\section{Acknowledgments}

Work supported in part by the Human Connectome Project (1U54MH091657-01) from the $16 \mathrm{NIH}$ Institutes and Centers that Support the NIH Blueprint for Neuroscience Research, and NIH grants, R01 EB000331, R01 EB008645, P30 NS057091, and P41 RR08079. The 7 T magnet purchase was funded in part by NSF DBI-9907842 and NIH S10 RR1395 and the KECK Foundation.

\section{References}

Bandettini, P.A., Wong, E.C., Hinks, R.S., Tikofsky, R.S., Hyde, J.S., 1992. Time course EPI of human brain function during task activation. Magn. Reson. Med. 25, 390-397.

Bianciardi, M., Fukunaga, M., van Gelderen, P., Horovitz, S.G., de Zwart, J.A., Duyn, J.H. 2009a. Modulation of spontaneous fMRI activity in human visual cortex by behavioral state. Neuroimage 45, 160-168.

Bianciardi, M., Fukunaga, M., van Gelderen, P., Horovitz, S.G., de Zwart, J.A., Shmueli, K., Duyn, J.H., 2009b. Sources of functional magnetic resonance imaging signal fluctuations in the human brain at rest: a 7 T study. Magn. Reson. Imaging 27, 1019-1029.

Bianciardi, M., van Gelderen, P., Duyn, J.H., Fukunaga, M., de Zwart, J.A., 2009c. Making the most of fMRI at $7 \mathrm{~T}$ by suppressing spontaneous signal fluctuations. Neuroimage 44, 448-454. 
Bianciardi, M., Fukunaga, M., van Gelderen, P., de Zwart, J.A., Duyn, J.H., 2011. Negative BOLD-fMRI signals in large cerebral veins. J. Cereb. Blood Flow Metab. 31, 401-412. doi:10.1038/jcbfm.2010.164.

Birn, R.M., Diamond, J.B., Smith, M.A., Bandettini, P.A., 2006. Separating respiratoryvariation-related fluctuations from neuronal-activity-related fluctuations in fMRI. Neuroimage 31, 1536-1548

Birn, R.M., Murphy, K., Bandettini, P.A., 2008. The effect of respiration variations on independent component analysis results of resting state functional connectivity. Hum. Brain Mapp. 29, 740-750.

Biswal, B.B., Mennes, M., Zuo, X.-N., Gohel, S., Kelly, C., Smith, S.M., Beckmann, C.F. Adelstein, J.S., Buckner, R.L., Colcombe, S., Dogonowski, A.-M., Ernst, M., Fair, D., Hampson, M., Hoptman, M.J., Hyde, J.S., Kiviniemi, V.J., Kötter, R., Li, S.-J., Lin, C.-P., Lowe, M.J., Mackay, C., Madden, D.J., Madsen, K.H., Margulies, D.S., Mayberg, H.S., McMahon, K., Monk, C.S., Mostofsky, S.H., Nagel, B.J., Pekar, J.J., Peltier, S.J., Petersen, S.E., Riedl, V., Rombouts, S.A.R.B., Rypma, B., Schlaggar, B.L., Schmidt, S., Seidler, R.D. Siegle, G.J., Sorg, C., Teng, G.-J., Veijola, J., Villringer, A., Walter, M., Wang, L., Weng, X.-C., Whitfield-Gabrieli, S., Williamson, P., Windischberger, C., Zang, Y.-F., Zhang, H.-Y., Castellanos, F.X., Milham, M.P., 2010. Toward discovery science of human brain function. Proc. Natl. Acad. Sci. U. S. A. 107, 4734-4739.

Buckner, R.L., Snyder, A.Z., Shannon, B.J., LaRossa, G., Sachs, R., Fotenos, A.F., Sheline Y.I., Klunk, W.E., Mathis, C.A., Morris, J.C., Mintun, M.A., 2005. Molecular, structural, and functional characterization of Alzheimer's disease: evidence for a relationship between default activity, amyloid, and memory. J. Neurosci. 25 , 7709-7717.

Calhoun, V.D., Adali, T., Pearlson, G.D., Pekar, J.J., 2001. Spatial and tempora independent component analysis of functional MRI data containing a pair of task-related waveforms. Hum. Brain Mapp. 13, 43-53.

Cheng, K., Waggoner, R.A., Tanaka, K., 2001. Human ocular dominance columns as revealed by high-field functional magnetic resonance imaging. Neuron 32, 359-374

Damoiseaux, J.S., Rombouts, S.A.R.B., Barkhof, F., Scheltens, P., Stam, C.J., Smith, S.M., Beckmann, C.F., 2006. Consistent resting-state networks across healthy subjects. Proc. Natl. Acad. Sci. U. S. A. 103, 13848-13853.

Duyn, J.H., van Gelderen, P., Li, T.-Q., de Zwart, J.A., Koretsky, A.P., Fukunaga, M., 2007 High-field MRI of brain cortical substructure based on signal phase. Proc. Natl. Acad. Sci. U. S. A. 104, 11796-11801.

Esposito, F., Scarabino, T., Hyvarinen, A., Himberg, J., Formisano, E., Comani, S., Tedeschi, G., Goebel, R., Seifritz, E., Di Salle, F., 2005. Independent component analysis of fMR group studies by self-organizing clustering. Neuroimage 25, 193-205.

Esposito, F., Aragri, A., Pesaresi, I., Cirillo, S., Tedeschi, G., Marciano, E., Goebel, R., Di Salle, F., 2008. Independent component model of the default-mode brain function: combining individual-level and population-level analyses in resting-state fMRI Magn. Reson. Imaging 26, 905-913.

Feinberg, D.A., Oshio, K., 1994. Phase errors in multi-shot echo planar imaging. Magn Res Med 32, 535-539.

Feinberg, D.A., Moeller, S., Smith, S.M., Auerbach, E.J., Ramanna, S., Glasser, M.F., Miller K.L., Ugurbil, K., Yacoub, E., 2010. Multiplexed Echo Planar Imaging for Sub-second Whole Brain FMRI and Fast Diffusion Imaging. PLoS ONE 5 (12), e15710. doi:10.1371/journal.pone.0015710.

Fischl, B., Sereno, M.I., Tootell, R.B., Dale, A.M., 1999. High-resolution intersubject averaging and a coordinate system for the cortical surface. Hum. Brain Mapp. 8, $272-284$.

Formisano, E., Esposito, F., Di Salle, F., Goebel, R., 2004. Cortex-based independent component analysis of fMRI time series. Magn. Reson. Imaging 22, 1493-1504.

Fox, M.D., Greicius, M.D., 2010. Clinical applications of resting state functional connectivity. Front. Syst. Neurosci. 4, 19.

Frahm, J., Merboldt, K.D., Hänicke, W., Kleinschmidt, A., Boecker, H., 1994. Brain or veinoxygenation or flow? On signal physiology in functional MRI of human brain activation. NMR Biomed. 7, 45-53.

Garrity, A.G., Pearlson, G.D., McKiernan, K., Lloyd, D., Kiehl, K.A., Calhoun, V.D., 2007. Aberrant "default mode" functional connectivity in schizophrenia. Am. J. Psychiatry $164,450-457$.

Goebel, R., Esposito, F., Formisano, E., 2006. Analysis of functional image analysis contest (FIAC) data with brainvoyager QX: from single-subject to cortically aligned group general linear model analysis and self-organizing group independent component analysis. Hum. Brain Mapp. 27, 392-401.

Greicius, M.D., Krasnow, B., Reiss, A.L., Menon, V., 2003. Functional connectivity in the resting brain: a network analysis of the default mode hypothesis. Proc. Natl. Acad. Sci. U. S. A. $100,253-258$

Greicius, M.D., Srivastava, G., Reiss, A.L., Menon, V., 2004. Default-mode network activity distinguishes Alzheimer's disease from healthy aging: evidence from functional MRI. Proc. Natl. Acad. Sci. U. S. A. 101, 4637-4642.

Haacke, E.M., Brown, R.W., Thomphson, M.R., Venkatesan, R., 1999. Magnetic resonance imaging: physical principles and sequence design. Magnetic Resonance Imaging: Physical Principles and Sequence Design. John Wiley \& Sons, Inc. New York, p. 914.

Hagmann, P., Cammoun, L., Gigandet, X., Meuli, R., Honey, C.J., Wedeen, V.J., Sporns, O. 2008. Mapping the structural core of human cerebral cortex. PLoS Biol. 6, e159.

Harel, N., Lin, J., Moeller, S., Ugurbil, K., Yacoub, E., 2006. Combined imaging histological study of cortical laminar specificity of fMRI signals. Neuroimage 29 879-887.

Honey, C.J., Sporns, O., Cammoun, L., Gigandet, X., Thiran, J.P., Meuli, R., Hagmann, P. 2009. Predicting human resting-state functional connectivity from structural connectivity. Proc. Natl. Acad. Sci. U. S. A. 106, 2035-2040.

Hyvarinen, 1999. Fast and robust fixed-point algorithms for independent component analysis. Neural Netw. IEEE Trans. 10, 626-634.
Hyvarinen, A., Karhunen, J., Oja, E., 2001. Independent Component Analysis. Wiley. Kim, S.G., Hendrich, K., Hu, X., Merkle, H., Uğurbil, K., 1994. Potential pitfalls of functional MRI using conventional gradient-recalled echo techniques. NMR Biomed. 7, 69-74.

Kwong, K.K., Belliveau, J.W., Chesler, D.A., Goldberg, I.E., Weisskoff, R.M., Poncelet, B.P. Kennedy, D.N., Hoppel, B.E., Cohen, M.S., Turner, R., 1992. Dynamic magnetic resonance imaging of human brain activity during primary sensory stimulation. Proc. Natl. Acad. Sci. U. S. A. 89, 5675-5679.

Lai, S., Hopkins, A.L., Haacke, E.M., Li, D., Wasserman, B.A., Buckley, P., Friedman, L., Meltzer, H., Hedera, P., Friedland, R., 1993. Identification of vascular structures as a major source of signal contrast in high resolution 2D and 3D functional activation imaging of the motor cortex at $1.5 \mathrm{~T}$ : preliminary results. In. Magn. Reson. Med. 30 , 387-392.

Logothetis, N.K., Pauls, J., Augath, M., Trinath, T., Oeltermann, A., 2001. Neurophysiological investigation of the basis of the fMRI signal. Nature 412,150-157.

Lütcke, H., Merboldt, K.-D., Frahm, J., 2006. The cost of parallel imaging in functional MRI of the human brain. Magn. Reson. Imaging 24, 1-5

Mansfield, P., 1977. Multi-planar image formation using NMR spin echoes. J. Phys. C Solid State Phys. 10, 55-58.

McKeown, M.J., Makeig, S., Brown, G.G., Jung, T.P., Kindermann, S.S., Bell, A.J., Sejnowski, T.J., 1998. Analysis of fMRI data by blind separation into independent spatial components. Hum. Brain Mapp. 6, 160-188.

McKinnon, G.C., 1993. Ultrafast interleaved gradient-echo-planar imaging on a standard scanner. Magn. Reson. Med. 30, 609-616.

Menon, R.S., Ogawa, S., Tank, D.W., Uğurbil, K., 1993. Tesla gradient recalled echo characteristics of photic stimulation-induced signal changes in the human primary visual cortex. Magn. Reson. Med. 30, 380-386.

Menon, R.S., Ogawa, S., Strupp, J.P., Uğurbil, K., 1997. Ocular dominance in human V1 demonstrated by functional magnetic resonance imaging. J. Neurophysiol. 77, 2780-2787.

Moeller, S., Van de Moortele, P.-F., Goerke, U., Adriany, G., Ugurbil, K., 2006. Application of parallel imaging to fMRI at 7 Tesla utilizing a high 1D reduction factor. Magn. Reson. Med. 56, 118-129.

Moeller, S., Yacoub, E., Olman, C.A., Auerbach, E., Strupp, J., Harel, N., Uğurbil, K., 2010. Multiband multislice GE-EPI at 7 tesla, with 16-fold acceleration using partial parallel imaging with application to high spatial and temporal whole-brain fMRI. Magn. Reson. Med. 63, 1144-1153.

Mugler III, J.P., Brookman, J.R., 1990. Three dimensional magnetization-prepared rapid gradient-echo imaging (3D MPRAGE). Magn. Reson. Med. 15, 152-157.

Ogawa, S., Tank, D.W., Menon, R., Ellermann, J.M., Kim, S.G., Merkle, H., Ugurbil, K., 1992. Intrinsic signal changes accompanying sensory stimulation: functional brain mapping with magnetic resonance imaging. Proc. Natl. Acad. Sci. U. S. A. 89, 5951-5955.

Olman, C.A., Van De Moortele, P.-F., Schumacher, J.F., Guy, J.R., Ugurbil, K., Yacoub, E., 2010. Retinotopic mapping with spin echo BOLD at 7 T. Magn. Reson. Imaging 28 (9), 1258-1269.

Polimeni, J.R., Fischl, B., Greve, D.N., Wald, L.L., 2010. Laminar analysis of 7 T BOLD using an imposed spatial activation pattern in human V1. Neuroimage 52, 1334-1346.

Poser, B.A., Norris, D.G., 2009. Investigating the benefits of multi-echo EPI for fMRI at 7 T. Neuroimage 45, 1162-1172.

Poser, B.A., Koopmans, P.J., Witzel, T., Wald, L.L., Barth, M., 2010. Three dimensional echo-planar imaging at 7 Tesla. Neuroimage 51, 261-266.

Pruessmann, K.P., Weiger, M., Scheidegger, M.B., Boesiger, P., 1999. SENSE: sensitivity encoding for fast MRI. Magn. Reson. Med. 42, 952-962.

Raichle, M.E., MacLeod, A.M., Snyder, A.Z., Powers, W.J., Gusnard, D.A., Shulman, G.L., 2001. A default mode of brain function. Proc. Natl. Acad. Sci. U. S. A. 98, 676-682.

Segebarth, C. Belle, V., Delon, C. Massarelli, R., Decety, J., Le Bas, J.F., Décorps, M. Benabid, A.L., 1994. Functional MRI of the human brain: predominance of signals from extracerebral veins. Neuroreport 5, 813-816.

Shmuel, A., Yacoub, E., Chaimow, D., Logothetis, N.K., Ugurbil, K., 2007. Spatio-temporal point-spread function of fMRI signal in human gray matter at 7 Tesla. Neuroimage 35, 539-552.

Sodickson, D.K., Manning, W.J., 1997. Simultaneous acquisition of spatial harmonics (SMASH): fast imaging with radiofrequency coil arrays. Magn. Reson. Med. 38, 591-603.

Sperling, R.A., Laviolette, P.S., O'Keefe, K., O'Brien, J., Rentz, D.M., Pihlajamaki, M., Marshall, G., Hyman, B.T., Selkoe, D.J., Hedden, T., Buckner, R.L., Becker, J.A., Johnson, K.A., 2009. Amyloid deposition is associated with impaired default network function in older persons without dementia. Neuron 63, 178-188.

Tedeschi, G., Trojsi, F., Tessitore, A., Corbo, D., Sagnelli, A., Paccone, A., D'Ambrosio, A., Piccirillo, G., Cirillo, M. Cirillo, S., Monsurrò, M.R., Esposito, F. 2010. Interaction between aging and neurodegeneration in amyotrophic lateral sclerosis. Neurobiol. Aging. doi:10.1016/j.neurobiolaging.2010.07.011.

Triantafyllou, C., Hoge, R.D., Krueger, G., Wiggins, C.J., Potthast, A., Wiggins, G.C., Wald, L.L. 2005. Comparison of physiological noise at 1.5 T, $3 \mathrm{~T}$ and $7 \mathrm{~T}$ and optimization of fMRI acquisition parameters. In: Neuroimage 26, 243-250.

Ugurbil, K., Adriany, G., Andersen, P., Chen, W., Garwood, M., Gruetter, R., Henry, P.-G., Kim, S.-G., Lieu, H., Tkac, I., Vaughan, J.T., van De Moortele, P.-F., Yacoub, E., Zhu, X.-H., 2003. Ultrahigh field magnetic resonance imaging and spectroscopy. Magn. Reson. Imaging 21, 1263-1281.

Uğurbil, K., Adriany, G., Andersen, P., Chen, W., Garwood, M., Gruetter, R., Henry, P.-G., Kim, S.-G, Lieu, H., Tkac, I, Vaughan, T, Van De Moortele, P.-F, Yacoub, E., Zhu, X.-H, 2003a. Ultrahigh field magnetic resonance imaging and spectroscopy. Magn. Reson. Imaging $21,1263-1281$

Uğurbil, K., Toth, L., Kim, D.S., 2003b. How accurate is magnetic resonance imaging of brain function? Trends Neurosci. 26, 108-114. 
Van De Moortele, P.-F., Auerbach, E.J., Olman, C.A., Yacoub, E., Ugurbil, K., Moeller, S. 2009. T1 weighted brain images at 7 Tesla unbiased for proton density, T2 contrast and RF coil receive B1 sensitivity with simultaneous vessel visualization. Neuroimage 46, 432-446.

van der Zwaag, W., Francis, S.T., Head, K., Peters, A.M., Gowland, P.A., Morris, P.G., Bowtell, R., 2009a. fMRI at 1.5, 3 and 7 T: characterising BOLD signal changes. In: Neuroimage 47, 1425-1434.

van der Zwaag, W., Marques, J.P., Hergt, M., Gruetter, R., 2009b. Investigation of highresolution functional magnetic resonance imaging by means of surface and array radiofrequency coils at 7 T. Magn. Reson. Imaging 27, 1011-1018.

Vaughan, J.T., Garwood, M., Collins, C.M., Liu, W., DelaBarre, L., Adriany, G., Andersen, P., Merkle, H., Goebel, R., Smith, M.B., Ugurbil, K., 2001. 7 T vs. 4 T: RF power, homogeneity, and signal-to-noise comparison in head images. In: Magn. Reson. Med. 46, 24-30.

Wielopolski, P.A., Manning, W.J., Edelman, R.R., 1995. Single breath-hold volumetric imaging of the heart using magnetization-prepared 3-dimensional segmented echo planar imaging. J. Magn. Reson. Imaging 5, 403-409.

Wiesinger, F., Van de Moortele, P.-F., Adriany, G., De Zanche, N., Ugurbil, K., Pruessmann, K.P., 2006. Potential and feasibility of parallel MRI at high field. NMR Biomed. 19, 368-378.
Yacoub, E., Shmuel, A., Pfeuffer, J., van De Moortele, P.F., Adriany, G., Andersen, P. Vaughan, J.T., Merkle, H., Ugurbil, K., Hu, X., 2001. Imaging brain function in humans at 7 Tesla. Magn. Reson. Med. 45, 588-594.

Yacoub, E., Duong, T.Q., van De Moortele, P.-F., Lindquist, M., Adriany, G., Kim, S.-G., Ugurbil, K., Hu, X., 2003. Spin-echo fMRI in humans using high spatial resolutions and high magnetic fields. Magn. Reson. Med. 49, 655-664.

Yacoub, E., Van De Moortele, P.-F., Shmuel, A., Ugurbil, K., 2005. Signal and noise characteristics of Hahn SE and GE BOLD fMRI at $7 \mathrm{~T}$ in humans. Neuroimage 24 738-750.

Yacoub, E., Shmuel, A., Logothetis, N.K., Ugurbil, K., 2007. Robust detection of ocular dominance columns in humans using Hahn Spin Echo BOLD functional MRI at 7 Tesla. Neuroimage 37, 1161-1177.

Yacoub, E., Harel, N., Ugurbil, K., 2008. High-field fMRI unveils orientation columns in humans. Proc. Natl. Acad. Sci. U. S. A. 105, 10607-10612.

Yang, Q.X., Wang, J., Zhang, X., Collins, C.M., Smith, M.B., Liu, H., Zhu, X.-H., Vaughan, J.T. Ugurbil, K., Chen, W., 2002. Analysis of wave behavior in lossy dielectric samples at high field. Magn. Reson. Med. 47, 982-989.

Zhao, F., Wang, P., Hendrich, K., Ugurbil, K., Kim, S.-G., 2006. Cortical layer-dependent BOLD and CBV responses measured by spin-echo and gradient-echo fMRI: insights into hemodynamic regulation. Neuroimage 30, 1149-1160. 